\title{
Tinospora Cordifolia Leaves Derived Carbon Dots For Cancer Cell Bioimaging, Free Radical Scavenging, And Fe3+ Sensing Applications
}

\section{Debadatta Mohapatra}

IIT BHU: Indian Institute of Technology BHU Varanasi

\section{Ravi Pratap}

IIT BHU: Indian Institute of Technology BHU Varanasi

\section{Vivek Pandey}

Banaras Hindu University

\section{Pawan K. Dubey}

Banaras Hindu University

\section{Ashish K. Agrawal}

IIT BHU: Indian Institute of Technology BHU Varanasi

\section{Avanish S. Parmar}

IIT BHU: Indian Institute of Technology BHU Varanasi

Alakh Niranjan Sahu ( $\nabla$ ansahu.phe@iitbhu.ac.in ) Indian Institute of Technology BHU Varanasi https://orcid.org/0000-0001-5234-0021

\section{Research Article}

Keywords: Carbon dots, Green chemistry, Bioimaging, Fe3+ Sensing, Radical scavenging

Posted Date: September 20th, 2021

DOl: https://doi.org/10.21203/rs.3.rs-833653/v1

License: (9) (i) This work is licensed under a Creative Commons Attribution 4.0 International License. Read Full License

Version of Record: A version of this preprint was published at Journal of Fluorescence on November 13th, 2021. See the published version at https://doi.org/10.1007/s10895-021-02846-6. 
Tinospora cordifolia Leaves Derived Carbon dots for Cancer Cell Bioimaging, Free radical Scavenging, and $\mathrm{Fe}^{3+}$ Sensing Applications

Debadatta Mohapatra ${ }^{1}$, Ravi Pratap ${ }^{2}$, Vivek Pandey ${ }^{3}$, Pawan K. Dubey ${ }^{3}$, Ashish K. Agrawal ${ }^{1}$, Avanish S. $\operatorname{Parmar}^{2} \&$ Alakh N. Sahu ${ }^{1 *}$

${ }^{1}$ Phytomedicine Research Lab., Department of Pharmaceutical Engineering \& Technology, IIT (BHU), Varanasi221005, Uttar Pradesh, India

${ }^{2}$ Department of Physics, IIT (BHU), Varanasi 221005, Uttar Pradesh, India

${ }^{3}$ Centre for Genetics Disorders, Institute of Science, Banaras Hindu University, Varanasi 221005, Uttar Pradesh, India

ORCID iD:

Debadatta Mohapatra: 0000-0003-3044-8706

Ravi Pratap: 0000-0002-3828-5051

Vivek Pandey: 0000-0002-1390-133X

Pawan K. Dubey:

Avanish S. Parmar:

Ashish K. Agrawal: 0000-0002-7302-3647

Alakh N Sahu: 0000-0002-2378-6179

* Corresponding author:

Alakh N Sahu

E-Mail: ansahu.phe@iitbhu.ac.in

Tel.: +919451137862 


\begin{abstract}
Herein, we report the fabrication of Tinospora cordifolia leaves-derived carbon dots (TCLCDs) from aqueous extract of leaves as carbon source via simple, environmental friendly, hydrothermal carbonization (HTC) technique. The synthesized TCLCDs were characterized for their physicochemical properties and further explored for in-vitro cancer cell bioimaging, radical scavenging, and metal ion sensing. The synthesized TCLCDs showed excitation-dependent emission property with maximum emission at $435 \mathrm{~nm}$ under the excitation of $350 \mathrm{~nm}$. The High-Resolution Transmission Electron Microscopy (HRTEM) results revealed a roughly spherical shape with an average diameter of $5.47 \mathrm{~nm}$. The diffused ring pattern of Selected Area Electron Diffraction (SAED) and halo diffraction pattern of X-ray diffraction (XRD) disclosed their amorphous nature. The Energy Dispersive X-ray (EDX) showed the existence of $\mathrm{C}, \mathrm{N}$, and $\mathrm{O}$. The Fourier-transform infrared spectroscopy (FTIR) revealed the presence of - $\mathrm{OH},-\mathrm{NH},-\mathrm{CN}$, and - $\mathrm{CH}$ groups. The TCLCDs showed excellent cellular biocompatibility with dosedependent bioimaging results in melanoma (B16F10) and cervical cancer (SiHa) cell lines. Also, they exhibited excellent scavenging of free radicals with an $\mathrm{IC}_{50}$ value of $0.524 \mathrm{mg} / \mathrm{mL} \&$ selective $\mathrm{Fe}^{3+}$ ion sensing with a detection limit of $0.414 \mu \mathrm{M}$. Further, they exerted excellent bacterial biocompatibility, photostability, and thermal stability. The overall results reflected their potential for in-vitro cancer cell bioimaging, free radical scavenging, and selective $\mathrm{Fe}^{3+}$ ion sensing.
\end{abstract}

Keywords: Carbon dots, Green chemistry, Bioimaging, $\mathrm{Fe}^{3+}$ Sensing, Radical scavenging. 


\section{Introduction}

Carbon dots (CDs) are a new class of zero-dimensional fluorescent carbonaceous nanomaterials with sizes $<10$ $\mathrm{nm}$, basically composed of carbon, nitrogen, oxygen, and hydrogen [1-4]. Due to their remarkable fluorescent ability, tunable fluorescence property, facile synthesis, high aqueous solubility, excellent photostability, high sensitivity, greater selectivity towards specific analytes, chemical inertness, negligible toxicity, favorable biocompatibility, eco-friendly and non-hazardous nature, they possess advantages over conventional organic dyes and semiconductor quantum dots (QDs) $[1,5,2,4]$. Furthermore, the flexibility in surface modification and functionalization of CDs with heteroatoms, such as boron, nitrogen, phosphorous, sulfur, and silane, has opened many possibilities for enhancing the fluorescent properties $[1,4]$.

The presence of various functional groups on the CDs frame allows surface functionalization and passivation. Hence their spectrum of utility has been expanded towards various fields, such as bioimaging, biomedicine, drug delivery, cancer theranostics, photodynamic therapy, gene therapy, detection of drugs and other molecules, biosensing, catalysis, fluorescent ink, light-emitting diode, optics devices, etc. [1,4,6-8,5,9].

In general, the synthetic approaches for CDs include top-down (e.g., arc-discharge, laser ablation, chemical, electrochemical exfoliation, and oxidative acid treatment methods) and bottom-up approaches (e.g., hydrothermal-carbonization, microwave-assisted carbonization, ultrasonic, thermal combustion, and acid treatment) $[1,5,9,2,4]$. The bottom-up approaches are more popular due to the cost-effectiveness, simplicity of synthesis, and ecofriendly nature. Moreover, the hydrothermal-carbonization (HTC) technique is widely exploited to synthesize CDs simply with a narrow particle size distribution [10,5].

Natural products play a significant role in the holistic healthcare of human beings from the Vedic era to date. They are safe, efficacious, and readily available sources of medicaments. Around 506 new approved drugs from 19812019 are either from a natural product or their derivatives [11]. Crude plant materials (leaves, flower, stem, bark, and roots) and their extracts are used from time immemorial to manage and treat multiple diseases. Plants are rich sources of primary and secondary metabolites, which include numerous phytoconstituents. The high natural abundance of $\mathrm{C}, \mathrm{H}, \mathrm{N}$, and $\mathrm{O}$ in the phytoconstituents acts as a precursor for the synthesis of highly fluorescent CDs. The presence of various heteroatoms $(\mathrm{N}, \mathrm{P}, \mathrm{S})$ in the phytomolecule causes self-functionalization during the carbonization process without using any additional passivating agents. Various parts of plant, such as fruits, leaves, stems, roots, bark, seeds, bulbs, and flowers, have been well explored as precursors for the synthesis of CDs [12]. Plant materials, such as pineapple fruit [13], Reishi Mushroom [14], Holy Basil leaves [15], Kalmegh leaves [16,17], Guar Gum [18], Hemp leaves [19], Japanese Apricot [10], Sapodilla fruits [20], Dragon fruits [21], Coriander leaves [22], Henna leaves [23], and Magnolia Lily flower [24] have been exploited for the synthesis of CDs for various applications.

Tinospora cordifolia, commonly called Guduchi (Hindi name: Giloya), belongs to the family of Menispermaceae, is one of the well-known Ayurvedic medicinal plants. This plant is used traditionally to cure multiple diseases, such as jaundice, inflammation, skin diseases, rheumatism, urinary tract infection, diabetes, and anemia. Particularly, the leaves are reported to possess antioxidant, anti-gout, antiulcer, antipyretic, hepatoprotective, antidiabetic, and wound healing properties $[25,26]$. The broad pharmacology of the plant reflects the existence of 
diverse bioactive phytomolecules. The leaves are enriched in protein, terpenes, aldehydes, hydroquinone, fatty acids, phosphorus, and calcium [25,26]. Herein, the leaves are chosen as a natural precursor for the synthesis of CDs.

Bioimaging is mainly used to investigate biological assembly thoroughly. Ideal fluorescent probes for viable cell bioimaging should be highly fluorescent, nontoxic, biocompatible, chemically inert, water-soluble, and photostable. Most of the currently used semiconductor-based quantum dots (QDs) and fluorescent dyes are highly toxic, unstable, and poorly soluble, making them unsuitable for in vitro viable cell imaging. In this regard, CDs have become suitable agents as novel fluorescent probes for bioimaging applications [9]. In addition to this, due to their good optical properties, wide excitation spectra, tunable and emission spectra, CDs are attracting marvelous attention [27]. Cancer is the most aggressive and life-threatening disease devouring the lives of millions of individuals each year. Therefore, innovative techniques for the early diagnosis of cancer are becoming more and more important for obstructing tumor development. In this context, CDs may be a choice for early diagnosis. The surface functional groups on the CDs act as a ligand bound to the surface groups of cancer cells and penetrate more efficiently due to their nanostructure, thus acting as a fluorescent probe for fluorescent imaging. Many of the CDs have been well exploited for in vitro as well as in vivo cancer cell imaging [27-31].

Free radicals are unstable, highly active substances that are involved in many chain reactions and are responsible for numerous pathological conditions, including autoimmune disorders, arthritis, ulcerative colitis, cardiovascular disorders, neurodegenerative disorders, aging, cancer, and other chronic diseases [32-34].

Antioxidants scavenge the free radicals and lower the severity of pathological conditions. These antioxidants are generally produced inside the body or may be supplied externally. When bodies own defense system is insufficient to produce antioxidants, they need to be supplied externally. CDs have been well exploited as an antioxidant for scavenging various free radicals [35-37].

Out of various metal ions, the $\mathrm{Fe}^{3+}$ ion is an essential ion in life that participated in electronic transfer, oxygen metabolism, oxygen uptake, cell respiration, DNA and hemoglobin synthesis, and many cellular events. However, its deficiency and excess accumulation of $\mathrm{Fe}^{3+}$ ions lead to serious health issues, such as anemia, renal failure, $\beta$ thalassemia, tissue damage, hemochromatosis, Alzheimer's disease, organ failures, and eventually death [38,39]. For proper regulation of most of the biological functions, the $\mathrm{Fe}^{3+}$ ion should be within an optimal physiologic range. Hence, their concentration should be accurately monitored in biological and environmental samples. Conventional analytical methods for detection of $\mathrm{Fe}^{3+}$ ion include an optical sensor, dye-based sensor, mass spectroscopy, inductive coupled mass atomic emission spectrometry (ICP-AES), inductive coupled plasma mass spectroscopy (ICP-MS), ion-exchange chromatography, and plasmon resonance Raleigh scattering (PRRS) spectroscopy. However, these are sophisticated techniques, utilize expensive reagents, and are time-consuming $[39,40]$. Thus, the innovation of a novel sensing agent for quantitative and qualitative estimation of $\mathrm{Fe}^{3+}$ ion is essential. CDs with ion-sensing abilities that can selectively perceive specific ions are of enormous importance amongst the new generation sensors because of the critical role of ions in health and physiological events [28]. Many of the CDs have been well studied for sensing of $\mathrm{Fe}^{3+}$ ion [37,40-43]. 
In this experiment, we have explored the TC leaves as a precursor for the synthesis of Tinospora cordifolia leavesderived carbon dots (TCLCDs) by green chemistry, facile, eco-friendly HTC technique. The obtained clear dark brown dispersion of TCLCDs showed green fluorescence while visualized under Ultra-violet (UV) light. The synthesized TCLCDs were characterized for their physicochemical properties and biological activities. Their invitro cytotoxicity and bioimaging study was performed against B16F10 (metastatic murine melanoma) and SiHa (Human cervical cancer) cell lines. Further, the TCLCDs were characterized for free radical scavenging, metal ion sensing, bacterial biocompatibility, and physicochemical stabilities.

\section{Materials and methods}

\section{Materials}

Fresh leaves of Tinospora cordifolia were collected from the campus of Indian Institute of Technology, Banaras Hindu University, Varanasi, in the month of March, and the voucher specimen (DM/TCL/PHYMEDLAB/2020) was submitted to Phytomedicine Research Lab., Department of Pharmaceutical Engineering \& Technology IIT (BHU), Varanasi. Dulbecco's Modified Eagle's Medium (DMEM/F-12), Trypsin-EDTA solution 0.25\%, 3-(4, 5dimethylthiazol- 2-yl)-2, 5-diphenyltetrazolium bromide (MTT), dimethyl Sulfoxide (DMSO), 4',6-diamidino-2phenylindole (DAPI), L-Ascorbic acid, ciprofloxacin, were purchased from Sigma-Aldrich (Sigma Aldrich, Germany). The 1, 1-diphenyl-2-picrylhydrazyl (DPPH) was purchased from Sisco Research Laboratories Pvt. Ltd. (SRL, India). The $\mathrm{NaCl}, \mathrm{Kcl}, \mathrm{CaCl}_{2}, \mathrm{MgCl}_{2}, \mathrm{CuCl}_{2}, \mathrm{NH}_{4} \mathrm{Cl}$, were obtained from Sisco Research Laboratories, $\mathrm{BaCl}_{2}, \mathrm{HgCl}_{2}$, purchased from Fisher Scientific Pvt. Ltd., $\mathrm{AgNo}_{3}$ obtained from Merck, $\mathrm{FeCl}_{3}$ obtained from Finar Chemicals, $\mathrm{Na}_{2} \mathrm{HAsO}_{4}, \mathrm{NaAsO}_{2}$ were purchased from SD Fine Chemical Ltd. Quinine sulfate was purchased from G S Chemical Testing Lab and Allied Industries, New Delhi, India. Mueller-Hinton agar (MHA) media was purchased from Himedia. Syringe filter $(0.2 \mu \mathrm{m})$ was purchased from Pall Corporation (Pall-Gelman Supor Acrodisc $\left.{ }^{\circledR}\right)$. Millipore water was used throughout the study as per the requirements.

Preparation of aqueous extract and CDs

The cold maceration method was used to prepare Tinospora cordifolia leaves aqueous extract (TCLAE) by mixing partially pulverized fresh leaves with water at a ratio of 1:3 w/v. After 24 hours of maceration, the aqueous extract was filtered, collected, and utilized as a carbon precursor for CDs synthesis. The hydrothermal carbonization (HTC) method was used for the synthesis of Tinospora cordifolia leaves-derived carbon dots (TCLCDs) from TCLAE. Accurately $60 \mathrm{ml}$ of TCLAE was poured into a $200 \mathrm{~mL}$ Teflon-lined stainless-steel hydrothermal autoclave. The sample was exposed to $160^{\circ} \mathrm{C}$ for 8 hours in a muffle furnace. Then the autoclave was removed from the muffle furnace and allowed to cool slowly. The dark brown aqueous solution of TCLCDs was collected and centrifuged at $12000 \mathrm{rpm}$ for $15 \mathrm{~min}$ at $25^{\circ} \mathrm{C}$ to separate the larger particles. Then the solution of TCLCDs was filtered through a $0.2 \mu \mathrm{m}$ syringe filter (Pall-Gelman Supor Acrodisc $®$ ), wrapped by aluminum foil, and stored at $4^{\circ} \mathrm{C}$ until further use.

Instrumental characterization of TCLCDs

Surface morphology, selected area electron diffraction (SAED), and energy dispersive analysis of X-rays (EDAX) analysis were carried out by high-resolution transmission electron microscope (HRTEM, FEI, TECNAI G2 20 TWIN, USA) with HAADF detector, at $200 \mathrm{kV}$ using a carbon-coated copper grid (400 Mesh, 3.05mm diameter, 
Ted Pella). The TCLCDs solution was diluted two times with Millipore water, and $15 \mu \mathrm{L}$ of the sample was dropped onto the grid and dried. A minimum of 50 particles was analyzed by ImageJ software, and the average size was calculated. Ultraviolet-visible absorption spectra were recorded by spectrophotometer (Cary 60 UV Vis, Agilent Technologies). The fluorescence property of TCLCDs was analyzed by a fluorescence spectrophotometer (Fluorolog-HORIBA Jobin Yvon, France) using a Xenon lamp with a $1 \mathrm{~nm}$ slit width. The surface functional groups of TCLCDs were identified by Fourier Transform Infrared spectroscopy (Thermo Scientific Nicolet iS5 FTIR) spectrophotometer in the frequency range 4000- 400 wavenumbers $\left(\mathrm{cm}^{-1}\right)$. For studying the X-ray diffraction (XRD) pattern, the solution of TCLCDs was dropped onto a clean glass slide, dried at $50^{\circ}$ whole night for making a thin film. The dried film was analyzed by X-ray diffractometer (Rigaku Miniflex 600, DTEX Ultra, Desktop X-Ray Diffraction System) using $\mathrm{Cu}$ K $\alpha$ radiation ( $\lambda=1.54 \AA, 40 \mathrm{kV}$ and $15 \mathrm{~mA})$. The interplane distance (d-spacing) values for the TCLCDs are estimated using Bragg's equation eq.1.

$2 d \sin \theta=n \lambda$

where $\mathrm{d}$ is the interplane distance, $\theta$ is the position of the plane, $\mathrm{n}$ is a positive integer (1), and $\lambda$ is the wavelength of incident X-rays $(\lambda=1.54 \AA)$.

The interatomic distance (a) was calculated using eq.2.

$$
\frac{a}{\sqrt{h^{2}+k^{2}+l^{2}}}=d_{(h, l, k)}
$$

Where. " $\mathrm{d}$ " is the interplane distance, and h, k, and 1 are the Miller indices.

The pH of TCLCDs was measured by a digital pH meter (PC 700, Eutech, Singapore) which was previously calibrated with $\mathrm{pH} \mathrm{7,} \mathrm{pH} 4$, and pH10 buffer solutions. The sample was diluted five times with millipore water, and the $\mathrm{pH}$ was measured. Thermogravimetric analysis (TGA) was performed on a Shimadzu TGA-50 analyzer by heating dried TCLCDs $(4.268 \mathrm{mg})$ under the flow of $\mathrm{N}_{2}$ gas $(100 \mathrm{ml} / \mathrm{min})$ at the temperature rate of $10^{\circ} \mathrm{C} / \mathrm{min}$ up to $800^{\circ} \mathrm{C}$.

\section{Quantum Yield}

The Quantum yield was estimated using eq.3 by measuring the fluorescence intensity of aqueous solution of TCLCDs with quinine sulfate $\left(0.1 \mathrm{M} \mathrm{H}_{2} \mathrm{SO}_{4}\right.$ having Quantum yield of $\left.54 \%\right)$ as a standard reference compound $[20,44]$.

$Q_{C D s}=Q_{R} \frac{I_{C D s}}{I_{R}} \times \frac{A_{R}}{A_{C D S}} \times \frac{\eta^{2}{ }_{C D S}}{\eta^{2}{ }_{R}}$

where, 'Q' is the Quantum yield, subscripts "CDs" stands for carbon dots, and " $R$ " for reference standard. The "I" is the integrated intensity of luminescent spectra, "A" indicates the absorbance at exited wavelength, and " $\eta$ " indicates the refractive index of the solvent used. The quantum yield of TCLCDs was evaluated at the maximum excitation wavelength $(350 \mathrm{~nm})$. 
In-vitro cytotoxicity studies, biocompatibility, and live cancerous cell bioimaging

MTT assay was carried out to study the cytotoxic effects of TCLAE and TCLCDs on melanoma (B16F10) and cervical cancer ( $\mathrm{SiHa}$ ) cell lines. Above cell lines were obtained from National Centre for Cell Sciences (NCCS) Pune, India, and seeded (1× 10\% /well) with DMEM/F-12 media in a 96 well plate containing $10 \%$ fetal bovine serum (FBS), $50 \mathrm{unit} / \mathrm{mL}$ streptomycin, and penicillin, followed by incubation at $5 \% \mathrm{CO}_{2}$ atmosphere, $37{ }^{\circ} \mathrm{C}$ for $24 \mathrm{~h}$. Then the media was removed, washed thrice with phosphate buffer saline (10 mM PBS, pH 7.4), and further incubated with serum-free fresh media containing various concentrations of TCLAE and TCLCDs (50-1500 $\mu \mathrm{g} / \mathrm{mL}$ ) for $24 \mathrm{~h}$. Then the wells were washed with PBS solution. The sample solution was replaced with $200 \mu \mathrm{L}$ fresh medium (without FBS) containing $20 \mu \mathrm{L}$ of MTT solution $(5 \mathrm{mg} / \mathrm{mL})$, and cells were incubated for $4 \mathrm{~h}$ at $37^{\circ} \mathrm{C}$. Then MTT was replaced with $150 \mu \mathrm{L}$ of DMSO, mixed gently to dissolve formazan crystals. Finally, the absorbance was recorded by an ELISA microplate reader at $570 \mathrm{~nm}$. The percentage of cell viability was estimated by using eq. 4 .

$$
\% \text { cell viability }=\frac{A b s_{(\text {sample })}}{A b s_{(\text {Control })}} \times 100
$$

where Abs (sample) represents the absorbance of the plate treated with sample (TCLAE or TCLCDs), and Abs (Control) represents the absorbance of the plate without any treatment.

The cellular uptake of TCLCDs and cancer cell imaging was investigated by fluorescence microscopy. The cancer cells (B16F10 and SiHa) were cultured at a density of $1 \times 10^{5}$ cells per well in a 6-well plate containing the same media used for cytotoxicity study and incubated for $24 \mathrm{~h}$ in a $\mathrm{CO}_{2}$ incubator at $37^{\circ} \mathrm{C}$ for $24 \mathrm{~h}$. Then the media was replaced with TCLCDs $(0-300 \mu \mathrm{g} / \mathrm{mL})$ and further incubated for $24 \mathrm{~h}$. After $24 \mathrm{~h}$ incubation, the medium was discarded, and the cells were washed thrice with PBS, fixed by $4 \%$ paraformaldehyde for 30 min, followed by nuclear staining with DAPI. Then the images were captured by EVOS FLC Invitrogen fluorescence microscope (Life technologies).

Scavenging and sensing of free radicals

The free radical scavenging activities of aqueous extract (TCLAE) and prepared TCLCDs were investigated by the standard DPPH method. Ethanolic DPPH solution $(100 \mu \mathrm{M})$ was prepared freshly in a dark environment. Different volumes of TCLAE $(3.243 \mathrm{mg} / \mathrm{mL})$ and TCLCDs $(2.823 \mathrm{mg} / \mathrm{mL})$ were taken in $2 \mathrm{~mL}$ of microcentrifuge tube, and the volume was adjusted with water up to one milliliter to produce various concentrations of samples. Then $1 \mathrm{~mL}$ of the above-diluted samples was added to $2 \mathrm{~mL}$ of ethanolic DPPH solution to produce different concentrations of TCLAE $(0-0.67 \mathrm{mg} / \mathrm{mL})$ and TCLCDs $(0-0.583 \mathrm{mg} / \mathrm{mL})$ in the final volume $(3 \mathrm{~mL})$. The above samples were incubated in a dark environment for 30 minutes. Standard Vitamin-C was chosen as a positive control. Different volumes of the aqueous solution of Vitamin-C (100 $\mu \mathrm{g} / \mathrm{mL})$ were taken in a $2 \mathrm{~mL}$ of microcentrifuge tube, and the volume was adjusted up to $1 \mathrm{~mL}$ with water to obtain different concentrations. Further, $1 \mathrm{~mL}$ of diluted Vitamin-C was added to $2 \mathrm{~mL}$ of ethanolic DPPH solution to produce different concentrations $(0-8 \mu \mathrm{g} / \mathrm{mL})$ of Vitamin-C in the final $3 \mathrm{~mL}$ sample solution. Then, the percentage scavenging was estimated by eq.5. 


$$
\% \text { Scavenging }=\frac{A_{D P P H}-A_{D P P H+\text { Sample or Standard }}}{A_{D P P H}} \times 100
$$

where "A $A_{D P P H}$ " represents the absorbance of the DPPH without sample or standard and "A $A_{D P P H}+$ Sample or standard" is the absorbance of DPPH with sample or standard at $517 \mathrm{~nm}$. The concentration of samples and standards necessary to scavenge $50 \%$ of $\mathrm{DPPH}$, i.e., the $\mathrm{IC}_{50}$ value, was calculated from the calibration plot of percentage scavenging of DPPH radicals as a function of TCLAE or TCLCDs or Vitamin-C concentrations.

The free radical sensing activity of prepared TCLCDs was examined by determining the changes in the fluorescent intensity upon the addition of DPPH radical. Accurately $2 \mathrm{~mL}$ of diluted TCLCD $(0.704 \mathrm{mg} / \mathrm{mL})$ was added with $2 \mathrm{~mL}$ ethanolic DPPH solution of various concentrations to produce 10,30 , and $50 \mu \mathrm{M}$ of DPPH concentration in the final volume (i.e., in $4 \mathrm{~mL}$ ) and incubated for 30 minutes. An appropriate blank solution was prepared by mixing $2 \mathrm{~mL}$ of TCLCD $(0.704 \mathrm{mg} / \mathrm{mL})$ with $2 \mathrm{~mL}$ of ethanol. After incubation, the fluorescence spectra were recorded at $350 \mathrm{~nm}$.

Metal ion sensing

The metal ion sensing of TCLCDs was examined by fluorescence spectroscopy. Solutions of all the metal ions were prepared in water from their chemical salts. Initially, the selectivity of TCLCDs towards various metal ions $\left(\mathrm{Na}^{+}, \mathrm{K}^{+}, \mathrm{Mg}^{2+}, \mathrm{Ca}^{2+}, \mathrm{Fe}^{3+}, \mathrm{Ag}^{3+}, \mathrm{Hg}^{2+}, \mathrm{Ba}^{2+}, \mathrm{NH}_{4}^{+}, \mathrm{Cu}^{2}, \mathrm{As}^{3+}, \mathrm{As}^{5+}\right)$ was investigated by incubating TCLCDs with different metal ions and observing the change in fluorescence intensity. Briefly, $2 \mathrm{~mL}$ aqueous solutions of various metal ions were incubated (for 15 minutes) with a $2 \mathrm{~mL}$ solution of diluted TCLCDs $(0.704 \mathrm{mg} / \mathrm{mL})$ to produce $200 \mu \mathrm{M}$ of each metal ion in total $4 \mathrm{~mL}$ volume. After incubation, the fluorescence intensities were recorded with a slit width of $1 \mathrm{~nm}$ at the maximum excitation wavelength $(350 \mathrm{~nm})$. The metal ion, which causes a drastic change in the intensity, was noted.

Further, the sensitivity of TCLCDs towards selective metal ion $\left(\mathrm{Fe}^{3+}\right)$ was evaluated by fluorescence titrations by further incubating $2 \mathrm{~mL}$ of TCLCDs $(0.704 \mathrm{mg} / \mathrm{mL})$ with $2 \mathrm{~mL}$ of different concentrations of aqueous $\mathrm{Fe}^{3+}$ for 15 minutes to achieve the final concentration of metal ion from 20 to $1000 \mu \mathrm{M}$ in the total volume (i.e., $4 \mathrm{~mL}$ ). The fluorescence spectra and intensities were recorded at $350 \mathrm{~nm}$. The fluorescence quenching efficiency of metallic ions was evaluated using Stern-Volmer equation (eq.6) [41].

$$
\frac{F_{0}}{F}=K_{s v}[Q]+1
$$

Where $\mathrm{F}_{0}$ and $\mathrm{F}$ are the fluorescence intensities of TCLCDs in the absence and presence of metal ion, respectively, Ksv is the Stern-Volmer quenching constant, and Q represents the concentration of the metal ion. Then the limit of detection (LOD) of selected metal $\left(\mathrm{Fe}^{3+}\right)$ ion in water was estimated using eq.7.

$$
L O D=\frac{3 \sigma}{s}
$$

Where $\sigma$ is the standard deviation of $F_{0} / F$ values and $s$ is the slope of the linear line. 
Stability study

Photostability

The photostability of TCLCDs was checked by exposing the sample to UV light (365 nm) continuously for 0,15 , $30,45,60,75,90,105$, and 120 minutes and intermittently observing the fluorescent behavior by the naked eye and measuring the intensities by fluorescence spectroscopy.

pH stability

The $\mathrm{pH}$-dependent stability of TCLCDs was examined by a deliberate change in the $\mathrm{pH}$ value by the addition of different volumes of $0.1 \mathrm{~N} \mathrm{HCl}$ or $\mathrm{NaOH}$ and by observing the changes in the fluorescent intensities.

\section{Thermal stability}

The thermal stability of TCLCDs was studied by TGA analysis by examining the loss of weight with respect to temperature.

Antimicrobial activity and biocompatibility evaluation

The bacterial biocompatibility of TCLCDs was evaluated by disc diffusion assay through the determination of zone of inhibition as performed for antimicrobial activity evaluation. The assay was performed on clinically isolated Multi-Drug Resistance (MDR) type Gram-positive (e.g., Staphylococcus aureus and Enterococcus faecalis) and Gram-negative strains (e.g., Escherichia coli, Klebsiella pneumoniae, Edwardsiella tarda, and Aeromonas hydrophila). These bacterial strains previously cultured in Mueller-Hinton agar (MHA) media were received from the Department of Microbiology, Institute of Medical Science, BHU, Varanasi. From the above microbial cultures, each bacterial suspension (optical density of $0.5 \mathrm{McFarland}$ ) was prepared in isotonic saline solution separately. Then, sterile Petri dishes containing $60 \mathrm{ml}$ of sterile solidified MHA media were seeded with an appropriate quantity of bacterial suspension and initially incubated at $37^{\circ} \mathrm{C}$ for $30 \mathrm{~min}$. After incubation, $6 \mathrm{~mm}$ diameter of sterile filter paper discs were gently placed on seeded plates, and $10 \mu \mathrm{L}$ of each sample (sterilized by filtration through $0.45 \mu \mathrm{m}$ membrane filter) was dropped onto it. Aqueous ciprofloxacin (20 $\mu \mathrm{g} / \mathrm{disc})$ was used as a positive control. TCLAE $(259.5 \mu \mathrm{g} / \mathrm{disc})$ and TCLCDs $(259.5 \mu \mathrm{g} / \mathrm{disc})$ were used as test samples. One additional sterile disc impregnated with sterile water was used as a negative control, and the plates were incubated for $24 \mathrm{~h}$ at $37^{\circ} \mathrm{C}$. The biocompatibility of green synthesized TCLCDs was accessed by observing any zone of inhibition around the impregnated discs.

\section{Results and Discussion}

Synthesis of TCLCDs

In this work, we have explored the synthesis of CDs (TCLCDs) from the leaves of Tinospora cordifilia as a green precursor. Out of various top-down and bottom-up approaches, the HTC method was realized as an efficient technique for the synthesis of CDs because of its simple, ecofriendly, and nontoxic nature [5]. Due to the high natural abundance of $\mathrm{C}, \mathrm{H}, \mathrm{N}$, and $\mathrm{O}$ in the diverse chemical groups of Tinospora cordifilia leaves, they act as a precursor for the preparation of CDs without the use of any additional passivating agents. The presence of numerous phytoconstituents and functional groups available in the leaves cause the self-passivation of TCLCDs. 
After 8 hours of digestion at $160^{\circ} \mathrm{C}$, dark brown color solution was obtained, reflecting the effective carbonization and formation of CDs [45]. The synthesis of TCLCDs is schematically represented in Scheme 1. The appearance of green fluorescence under UV irradiation $(365 \mathrm{~nm})$ further supports the formation of CDs.

Surface morphology, SAED pattern, and EDX analysis

The HRTEM photomicrograph depicts the smaller, near-spherical nature of the particles (Figure 1.a and. Figure 1.b). The average particle size of 50 particles measured by ImageJ software was found to be $5.47 \mathrm{~nm}$, with most of the particles within the range of 4 to $6 \mathrm{~nm}$ (Figure 1.c). The SAED patterns showed diffused rings signifying the amorphous nature of the TCLCDs (Figure 1.d). The amorphous phase of TCLCDs indicated the proper synthesis of the CDs [41]. Furthermore, the elemental composition of TCLCDs was studied from EDAX spectra [21]. The EDAX spectra (Figure 1.e) depict the presence of C, N, O with their corresponding percentage (Inset data, Figure 1.e). The $\mathrm{C}, \mathrm{N}$, and $\mathrm{O}$ are the primary components of $\mathrm{CDs}$. The $\mathrm{Cu}$ spectra are due to the presence of $\mathrm{Cu}$ in the TEM grid. The higher percentage of $\mathrm{C}$ in the EDAX data reflecting the carbonaceous nature of TCLCDs.

Optical properties analysis

Initially, the optical properties of TCLCDs were studied by UV-vis absorption spectroscopy. The absorption spectra of TCLCDs and their precursor (TCLAE) are shown in Figure 2.a. The TCLCDs showed a sharp absorption peak at $270.23 \mathrm{~nm}$, ascribed to $\pi-\pi^{*}$ transition of aromatic $\mathrm{C}=\mathrm{C}$ bonds, and a low and wide absorption peak around $334.44 \mathrm{~nm}$ is attributed to $n-\pi^{*}$ transition of $\mathrm{C}=\mathrm{O}$ bond [46,37]. In contrast, the TCLAE showed two sharp peaks at $270 \mathrm{~nm}$ and $324 \mathrm{~nm}$. The spectrum of TCLCDs is slightly different from the spectrum of extract, which might be due to the carbonization and alteration of the chemical composition of various phytoconstituents during the HTC method.

Further, the optical properties were studied by fluorescence spectroscopy. The fluorescence emission spectra were recorded at various excitation wavelengths. As shown in Figure 2.b, with the increase of excitation wavelength from 335 to $350 \mathrm{~nm}$, the fluorescence intensities are gradually increased, ascribed to $\pi^{*}$ to $\pi$ transitions of graphitic carbon. In contrast, the fluorescence intensities are decreased remarkably, and the bathochromic shift was observed during excitation wavelength from 350 to $360 \mathrm{~nm}$. The excitation-dependent emission property is an intrinsic property of CDs $[47,48,41,37]$. Such phenomena are attributed to the existence of different functional groups such as amino, cyano, and hydroxyl groups on the surface of TCLCDs, which is consistent with the FTIR data [47]. A strong fluorescence emission peak centered at $435 \mathrm{~nm}$ is recorded under excitation at $350 \mathrm{~nm}$ (Figure 2.c). These fluorescent properties are mainly ascribed to quantum effect, radiative recombination of excitons, distributions of photoemissive traps on each CDs, and free zigzag sites with a carbene-like triplet ground state [48]. The fluorescence intensity of TCLCDs $(370.32 \mu \mathrm{g} / \mathrm{mL})$ at an excitation wavelength of $350 \mathrm{~nm}$ was found to be 27971.61 a.u. To further investigate the optical properties, the emission spectra were recorded for various concentrations of TCLCDs (Figure 2.d). The fluorescence intensity was found to be increased from 75.04 to $370.32 \mu \mathrm{g} / \mathrm{mL}$, while the intensities were found to be decreased further with increasing the concentration, which is due to the concentration quenching or self-quenching. This is because the emitted radiations are being absorbed and re-emitted by adjacent molecules before falling on the detector. The calculated Quantum yield of TCLCDs 
against quinine sulfate as the reference standard, measured at an excitation wavelength of $350 \mathrm{~nm}$, was found to be $3.7 \%$, comparable with the previous reports of CDs obtained by the green synthesis approach $[41,49,39]$.

Fluorescent ink

The aqueous solution of TCLCDs was used as fluorescent ink by injecting it into a vacant pen to write fluorescent words on filter paper (Figure 2.e and Figure 2.f). The photograph (Figure 2.f) displays the text "TCLCD", "IIT" and drawing of "stars", "dots" which are highly visible and distinct from the background while observed under UV light $(365 \mathrm{~nm})$. However, these text and drawings are invisible in the daylight (Figure 2.e), reflecting the potential of TCLCDs to be utilized as fluorescent ink. Due to their consistent fluorescence behavior, durability, easy washability, and biocompatibility, the green synthesized TCLCDs based fluorescent ink could be a better alternative for traditional fluorescent inks [24].

Surface functionality

The surface functional groups of TCLCDs were analyzed through FTIR spectroscopy (Figure 3.a). The broad peak at $3419.1 \mathrm{~cm}^{-1}$ was ascribed to O-H stretching of the alcoholic/phenolic group. A weak peak at $2933 \mathrm{~cm}^{-1}$ was due to $\mathrm{C}-\mathrm{H}$ stretching of alkane. The peaks at 1604.4 and $1401.9 \mathrm{~cm}^{-1}$ were assigned to N-H bending of primary amine and C-C stretching of aromatic carbon. The band at 1115.6 and $1079.4 \mathrm{~cm}^{-1}$ were ascribed to the stretching vibrations of the aliphatic $\mathrm{C}-\mathrm{N}$ group. The broad peak at $620.48 \mathrm{~cm}^{-1}$ was due to the $\mathrm{C}-\mathrm{H}$ bending of the alkyne group. The results of FTIR spectroscopy revealed the multifunctional nature of the TCLCDs.

Powder X-ray diffraction (XRD)

Figure 3.b presents the XRD pattern of TCLCDs. The diffraction pattern shows two sharp peaks at $29.34^{\circ}, 42.88^{\circ}$ and one broad peak at $60.04^{\circ} 2 \theta$, which are assigned to (002), (100) and (103) planes of graphitic carbon [48]. The XRD diffraction is in accordance with the SAED pattern. The estimated d-spacing values of TCLCDs were approximately $0.304 \mathrm{~nm}, 0.21 \mathrm{~nm}$, and $0.154 \mathrm{~nm}$ for C (002), C (100), and C (103) planes, respectively. The estimated interatomic distance values corresponding to C (002), C (100), and C (100) planes were found to be $0.608 \mathrm{~nm}, 0.21 \mathrm{~nm}$, and $0.486 \mathrm{~nm}$, respectively.

In-vitro cytotoxicity studies and cellular uptake studies

The in-vitro cytotoxicity potential of the extract (TCLAE) and prepared CDs (TCLCDs) on B16F10 (Melanoma) and SiHa (Cervical cancer) cell lines were examined by MTT assay. The percentage of cell viability against different concentrations of TCLAE or TCLCDs was shown in Figure 3.c and Figure 3.d. The percentage cell viability of both cancer cells was found to be nearer to $90 \%$, even at a very high concentration $(1500 \mu \mathrm{g} / \mathrm{mL}) \mathrm{of}$ TCLCDs. This result reflected the low cytotoxicity of the TCLCDs and inferred their potential use for viable cancer cell imaging [37]. The TCLAE showed low cytotoxicity against both cell lines at higher concentrations; however, the TCLCDs showed almost no cytotoxicity towards the taken cancer cell lines. The decreased cytotoxic activity of TCLCDs compared to TCLAE may be due to the degradation of phytoconstituents at a higher temperature during its synthesis via hydrothermal autoclaving. 
Considering the excellent fluorescence property, aqueous solubility, and sufficient cellular biocompatibility, the TCLCDs were employed as a fluorescent probe for viable cancer cell imaging. The bright-field images of B16F10 and SiHa cells treated with TCLCDs (Figure 4.a and Figure 4.b) clearly reflected the normal cellular morphology, verifying that TCLCDs possessed low toxicity. The TCLCDs treated cells showed green color fluorescence in both cell lines at the UV excitation wavelength (Figure 4.a and Figure 4.b). In contrast, the TCLCDs untreated cancer cells did not show any fluorescence. The cellular fluorescence was increased in a dose-dependent manner from $0-300 \mu \mathrm{g} / \mathrm{mL}$. The TCLCDs internalized successfully in the cancerous cells to the cytoplasmic portion as confirmed by nuclear counterstaining by DAPI [37,16].

Free radical scavenging activity and sensing

The DPPH model was utilized to study the free radical scavenging activity of TCLCDs and their precursor (TCLAE). DPPH is a nitrogen-containing free radical, which is deep purple in color. During reaction with radical scavengers, this deep purple color eventually changes to light yellow with respect to the scavenging potential of analytes [41]. The remaining DPPH radical in the solution was evaluated by recording the absorbance at $517 \mathrm{~nm}$ against the appropriate blank, and \% scavenging was estimated. The dose-dependent scavenging activity was found in both TCLAE and TCLCDs with gradual color change from a deep purple color to light yellow (Figure 5.a and Figure 5.b). This is further verified from the decrease in the absorbance intensity upon an increase in the concentrations of TCLAE $(0-0.67 \mathrm{mg} / \mathrm{mL})$ and TCLCDs $(0-0.583 \mathrm{mg} / \mathrm{mL})$ (Figure 5.c and Figure 5.d). The concentrations of TCLAE or TCLCDs were plotted against \% scavenging (Figure 5.e and Figure 5.f). During gradual increment in the concentration of TCLAE and TCLCDs, the percentage scavenging was increased gradually. The linear relationship was found within the TCLAE concentration of 0.237 to $0.67 \mathrm{mg} / \mathrm{mL}$ with the obtained regression equation $\mathrm{y}=38.701 \mathrm{x}+24.618$ and $\mathrm{R}^{2}$ value of 0.997 (Inset Figure 5.e). The obtained $\mathrm{IC}_{50}$ value of TCLAE from the equation was found to be $0.655 \mathrm{mg} / \mathrm{mL}$ (Inset Figure 5.e). Similarly, the linearity obtained within the TCLCDs concentration of 0.282 to $0.583 \mathrm{mg} / \mathrm{mL}$ with the obtained regression equation $\mathrm{y}=28.559 \mathrm{x}+35.015, \mathrm{R}^{2}$ value of 0.997 and $\mathrm{IC}_{50}$ value $0.524 \mathrm{mg} / \mathrm{mL}$ (Inset Figure 5.f). The $\mathrm{IC}_{50}$ value obtained for the positive control (Vitamin C) was found to be $6.715 \mu \mathrm{g} / \mathrm{mL}$ (Figure 5.g). The obtained $\mathrm{IC}_{50}$ value of TCLCDs is low as compared to the TCLAE. This might be due to the nanostructure, presence of surface defects, availability of unpaired electrons, and the high surface-to-volume ratio of TCLCDs, making them more reactive to scavenge free-radical at a lower concentration [50].

Upon exposure of different concentrations $(10,30$, and $50 \mu \mathrm{M})$ of DPPH to TCLCDs, the quenching in the fluorescent intensity was observed as compared to the blank solution (Figure 5.h). The quenching of the fluorescent intensity of TCLCDs is ascribed to the influence of electron donor or acceptor molecules inside the solution via an internal redox reaction among the excited state of CDs and analytes that donate or accept an electron [51,35]. Such phenomenon is termed photo-induced electron transfer (PET), in which the complex is produced due to the interaction between electron donor and the electron acceptor and returns to the ground state without emission of a photon, therefore decreasing the fluorescent intensity. Other probable mechanisms regarding the sensing and alteration of the fluorescence intensity include Forster resonance energy transfer (FRET), photo-induced charge transfer (PCT), and inner filter effect (IFE) [35]. Overall, the results from the DPPH sensing study were signifying the free radical sensing potential of prepared TCLCDs and their probable application in this area. 
Metal ion sensing

Fluorescent-based sensors have gained immense popularity all over the globe. Out of multiple dimensions, metal sensing is one of them. Metal sensing properties of green synthesized CDs were reported by various research groups [41,40,52]. To investigate the metal selectivity of TCLCDs, fluorescence intensities were observed in the presence of various metal ions. The relative reduction of fluorescence intensity of TCLCDs $(0.352 \mathrm{mg} / \mathrm{mL}) \mathrm{due}$ to the presence of different metal cations (each at a concentration of $200 \mu \mathrm{M}$ ) is represented in Figure 6.a.

The fluorescent intensity remained unchanged in the presence of $\mathrm{Na}^{+}, \mathrm{Mg}^{2+}, \mathrm{Ca}^{2+}, \mathrm{Ba}^{2+}, \mathrm{As}^{3+}$, and $\mathrm{As}^{5+}$ ions. The $\mathrm{Fe}^{3+}$ metal cations caused a marked reduction of the fluorescent intensity of TCLCDs, whereas the $\mathrm{Hg}^{2+} \mathrm{Cu}^{2}$, $\mathrm{NH}_{4}^{+}, \mathrm{K}^{+}$, and $\mathrm{Ag}^{3+}$ caused a slight reduction of intensity. The slight decrease in the fluorescent intensity is attributed to non-specific interaction between metal cations with surface functional groups of TCLCDs. Among all, $\mathrm{Fe}^{3+}$ causes a severe quenching effect. The bar diagram (Figure 6.a) clearly indicates almost half the reduction of initial fluorescence intensity by $\mathrm{Fe}^{3+}$ ion. The results reflecting higher selectivity of TCLCDs towards sensing of $\mathrm{Fe}^{3+}$ cation, which may be assigned to special interaction between surface functional groups $\left(-\mathrm{OH}\right.$ or $\left.-\mathrm{NH}_{2}\right)$ groups of TCLCDs and $\mathrm{Fe}^{3+}[53,41]$. The $\mathrm{Fe}^{3+}$ sensing property of some CDs was also reported previously $[38,53,40,22,54]$. The selective fluorescence quenching in the presence of $\mathrm{Fe}^{3+}$ is assigned to the transfer of the photoelectrons from multi-functionalized TCLCDs to $\mathrm{Fe}^{3+}$ cations $[55,56,40]$.

The sensitivity of TCLCDs $(0.352 \mathrm{mg} / \mathrm{mL})$ towards $\mathrm{Fe}^{3+}$ was examined by fluorescent titration by incubating it with different concentration $(0-1000 \mu \mathrm{M})$ of $\mathrm{Fe}^{3+}$ ion (Figure 6.b). A steady reduction of the fluorescence intensity of TCLCDs was found with a gradual increase in the $\mathrm{Fe}^{3+}$ concentration. Linearity exists within 0 to $100 \mu \mathrm{M}$ concentration with the corresponding regression equation $y=19302.86-43.919 x$. The correlation coefficient $\left(R^{2}\right)$ of 0.999 reflects a perfect linear correlation and strongest sensitivity towards $\mathrm{Fe}^{3+}$ ion (Figure 6.c). Further, the fluorescence quenching efficiency of TCLCDs was described with the Stern-Volmer plot to extrapolate a correlation coefficient of 0.995 in a concentration range of 10-100 $\mu \mathrm{M}$ (Figure 6.d). The corresponding regression equation was $\mathrm{y}=0.00294 \mathrm{x}+0.96126$.

The Stern-Volmer quenching constant $\left(\mathrm{K}_{\mathrm{sv}}\right)$ or slope of the linear fit was found to be 0.00294 , and the calculated LOD was $0.414 \mu \mathrm{M}$, which is well comparable with the previous reports on CDs for selective $\mathrm{Fe}^{3+}$ sensing $[41,38,52,40,37]$. Notably, the LOD value is remarkably lower than that of the maximum permissible level for $\mathrm{Fe}^{3+}$ ion in drinking water $(5.36 \mu \mathrm{M})$ as per World Health Organization (WHO) report [41]. Since our green synthesized TCLCDs can sense the $\mathrm{Fe}^{3+}$ far below the maximum permissible level, it may be used as $\mathrm{Fe}^{3+} \mathrm{sensor}^{2}$ to examine the $\mathrm{Fe}^{3+}$ content in drinking water.

Stability

Photostability

Constant fluorescence during UV exposure (i.e., the photostability) of CDs is essential for bioimaging study. To investigate photostability, the TCLCDs were studied under UV illumination at $365 \mathrm{~nm}$ (long UV). Various samples of TCLCDs were exposed to UV light for different time periods. No photobleaching was noticed at the end of the study, and the fluorescent behavior remained intact (Figure 7.a). For further confirmation, the 
fluorescent emission spectra (Figure 7.b) were recorded (at excitation wavelength $350 \mathrm{~nm}$ ) for the UV exposed samples, and the intensities were observed. No significant change in the intensity was noticed, reflecting the good photostability potential of prepared TCLCDs.

pH stability

The $\mathrm{pH}$ of TCLCDs was changed intentionally from $\mathrm{pH} 1$ to 13 , and the fluorescent spectra were recorded. A gradual increase in the fluorescent intensity was observed up to $\mathrm{pH} \mathrm{7,} \mathrm{after} \mathrm{which} \mathrm{the} \mathrm{intensity} \mathrm{was} \mathrm{dropped}$ significantly up to $\mathrm{pH} 13$ (Figure 7.c). The pH-dependent emission property is assigned to ionization of surface functional groups (-OH, -NH) as reported previously [22]. Since the fluorescent intensity is highest and remains constant at the physiological range of $\mathrm{pH}$ (from 7.0 to 7.4), it has the potential for in-vitro and in-vivo bioimaging applications [53].

\section{Thermal stability}

The thermal stability of TCLCDs was demonstrated by a TGA thermogram (Figure 7.d). It showed a four-step degradation pattern, with the first $2.39 \%$ loss of weight at $171.38{ }^{\circ} \mathrm{C}$ is attributed to the loss of water molecules and other weakly bounded molecules on the surface of TCLCDs. This slight weight loss was also representing the thermal stability of TCLCDs up to $171.38{ }^{\circ} \mathrm{C}$ [52,22]. Further, a continuous weight loss of $29.867 \%$ between $171.84{ }^{\circ} \mathrm{C}$ to $315.19^{\circ} \mathrm{C}, 21.076 \%$ between $315.19^{\circ} \mathrm{C}$ to $504.25^{\circ} \mathrm{C}$, and $22.65 \%$ between $504.25^{\circ} \mathrm{C}$ to $800{ }^{\circ} \mathrm{C}$ may be due to the degradation of strongly associated functional groups on the surface of TCLCDs [52,22]. Beyond $800{ }^{\circ} \mathrm{C}$, the curve leveled off.

\section{Bacterial biocompatibility}

The results of the disc diffusion assay were shown in Figure.8. All experiments were performed in triplicate. The positive control, ciprofloxacin, showed antimicrobial activity against all bacterial strains, signifying the antibiotic susceptibility of cultured microorganisms. However, the TCLAE and TCLCDs showed no zone of inhibition as observed with sterile water (negative control), representing the biocompatibility nature with all experimental bacterial strains. Thus, utilizing the fluorescence property of TCLCDs and due to its excellent bacterial biocompatibility, it can be used as a fluorescent probe for live bacterial cell imaging [49].

\section{Conclusions}

In summary, we have successfully fabricated green fluorescent carbon dots (TCLCDs) from the leaves of Tinospora cordifolia via a simple, one-step, and eco-friendly hydrothermal carbonization method. The TCLCDs displayed excitation-dependent emission property with maximum emission at $435 \mathrm{~nm}$ under the excitation of 350 $\mathrm{nm}$. The HRTEM and EDAX data reflected the near-spherical nature with $\mathrm{C}, \mathrm{N}$, and $\mathrm{O}$ as major elements. The SAED and XRD results reflected their amorphous nature. The FTIR result showed the presence of O-H, C-H, NH, C-C, C-N, C-H groups. The TCLCDs showed excellent biocompatibility with interesting dose-dependent bioimaging results in melanoma (B16F10) and cervical cancer (SiHa) cell lines. Moreover, it showed excellent selectivity and sensitivity to $\mathrm{Fe}^{3+}$ with a limit of detection of $0.414 \mu \mathrm{M}$; hence it may be used as an effective probe for $\mathrm{Fe}^{3+}$ sensing. Furthermore, the TCLCDs showed excellent radical scavenging against DPPH with an $\mathrm{IC}_{50}$ value of $0.524 \mathrm{mg} / \mathrm{mL}$. Also, it showed satisfactory results as fluorescent ink possesses sufficient bacterial 
biocompatibility, photostability, and thermal stability. Combining its simple and one-step eco-friendly synthetic method, excellent optical properties, sufficient biocompatibility, enough stability, the TCLCDs hold great promise for potential applications in cancer cell bioimaging, free radical scavenging, and $\mathrm{Fe}^{3+}$ ion sensing in pharmaceutical and biomedical fields.

\section{Declarations}

\section{Funding:}

The financial support for this work was provided as a scholarship to Debadatta Mohapatra by the Ministry of Human Resource Development (MHRD), government of India. Author Alakh N. Sahu is thankful to Department of Biotechnology (DBT), Ministry of Science \& Technology, Government of India, New Delhi, India, for providing the funding (Sanction order No. BT/PR25498/NER/95/1223/2017) for exploring phytochemical and pharmacological evaluations of bioactivity guided fractions of medicinal plants. Author Ashish K. Agrawal is thankful to Science \& Engineering Research Board (SERB), Department of Science and Technology (DST), New Delhi, India, for providing the funding (File No. SRG/2019/000150) for exploring the smart exosomes for drug delivery.

\section{Conflicts of interest:}

The authors declare that they have no conflicts of interest.

\section{Availability of data and material:}

All data recorded and generated during this research are included in this article.

\section{Code availability (software application)}

The data were generated using MS office package, 21 days free trial version of Origin Pro 2021 (Microcal Software, Inc., Northampton, Northampton, MA, USA), and ImageJ software (National Institutes of Health, Bethesda, MD).

\section{Authors' contributions}

Debadatta Mohapatra performed most experimental works, data collection, analysis, validation, interpretation, and wrote the original manuscript. Ravi Pratap and Vivek Pandey contributed to the experimentation, reviewed and edited the manuscript. Alakh N. Sahu, Avanish S. Parmar, Ashish K. Agrawal, and Pawan K. Dubey contributed to supervision, technical support, manuscript review, and editing functions.

Ethics approval: Not applicable 
Consent to participate: Not applicable

Consent for publication: Not applicable

\section{Acknowledgment:}

The authors are thankful to the Department of Pharmaceutical Engineering \& Technology, IIT (BHU); Department of Physics, IIT (BHU); Centre for Genetics Disorders, Institute of Science, Banaras Hindu University, and Central Instrument Facility, IIT (BHU), Varanasi, India for providing infrastructural and instrumental facilities. The facilities for microbiology work provided by the Department of Microbiology, IMS (BHU), Varanasi, India, are also greatly acknowledged. 


\section{References}

1. Hu Q, Gong X, Liu L, Choi MM (2017) Characterization and analytical separation of fluorescent carbon nanodots. J Nanomater 2017

2. Sciortino A, Cannizzo A, Messina F (2018) Carbon nanodots: A review-from the current understanding of the fundamental photophysics to the full control of the optical response. C 4 (4):67

3. Roy P, Chen P-C, Periasamy AP, Chen Y-N, Chang H-T (2015) Photoluminescent carbon nanodots: synthesis, physicochemical properties and analytical applications. Mater Today 18 (8):447-458

4. Jaleel JA, Pramod K (2018) Artful and multifaceted applications of carbon dot in biomedicine. J Control Release 269:302-321

5. Namdari P, Negahdari B, Eatemadi A (2017) Synthesis, properties and biomedical applications of carbon-based quantum dots: An updated review. Biomed Pharmacother 87:209-222

6. Wang Y, Kalytchuk S, Wang L, Zhovtiuk O, Cepe K, Zboril R, Rogach AL (2015) Carbon dot hybrids with oligomeric silsesquioxane: solid-state luminophores with high photoluminescence quantum yield and applicability in white light emitting devices. Chem Commun 51 (14):2950-2953

7. Wu Y-F, Wu H-C, Kuan C-H, Lin C-J, Wang L-W, Chang C-W, Wang T-W (2016) Multi-functionalized carbon dots as theranostic nanoagent for gene delivery in lung cancer therapy. Sci Rep 6:21170

8. Lim SY, Shen W, Gao Z (2015) Carbon quantum dots and their applications. Chem Soc Rev 44 (1):362-381

9. Peng Z, Han X, Li S, Al-Youbi AO, Bashammakh AS, El-Shahawi MS, Leblanc RM (2017) Carbon dots: biomacromolecule interaction, bioimaging and nanomedicine. Coord Chem Rev 343:256-277

10. Atchudan R, Edison TNJI, Sethuraman MG, Lee YR (2016) Efficient synthesis of highly fluorescent nitrogendoped carbon dots for cell imaging using unripe fruit extract of Prunus mume. Appl Surf Sci 384:432-441

11. Newman DJ, Cragg GM (2020) Natural products as sources of new drugs over the nearly four decades from 01/1981 to 09/2019. J Nat Prod 83 (3):770-803

12. Naik GG, Shah J, Balasubramaniam AK, Sahu AN (2021) Applications of natural product-derived carbon dots in cancer biology. Nanomedicine 16 (7):587-608

13. Gupta DA, Desai ML, Malek NI, Kailasa SK (2020) Fluorescence detection of Fe3+ ion using ultra-small fluorescent carbon dots derived from pineapple (Ananas comosus): Development of miniaturized analytical method. J Mol Struct 1216:128343

14. Tu Y, Wang S, Yuan X, Wei Y, Qin K, Zhang Q, Chen X, Ji X (2020) A novel fluorescent nitrogen, phosphorus-doped carbon dots derived from Ganoderma Lucidum for bioimaging and high selective two nitrophenols detection. Dyes Pigm 178:108316

15. Shukla D, Pandey FP, Kumari P, Basu N, Tiwari MK, Lahiri J, Kharwar RN, Parmar AS (2019) Label-Free Fluorometric Detection of Adulterant Malachite Green Using Carbon Dots Derived from the Medicinal Plant Source Ocimum tenuiflorum. ChemistrySelect 4 (17):4839-4847

16. Naik GG, Alam MB, Pandey V, Mohapatra D, Dubey PK, Parmar AS, Sahu AN (2020) Multi-Functional carbon dots from an ayurvedic medicinal plant for cancer cell Bioimaging Applications. J Fluoresc:1-12

17. Naik GG, Alam MB, Pandey V, Dubey PK, Parmar AS, Sahu AN (2020) Pink Fluorescent Carbon Dots Derived from the Phytomedicine for Breast Cancer Cell Imaging. ChemistrySelect 5 (23):6954-6960

18. Bajpai S, D'Souza A, Suhail B (2019) Carbon dots from Guar Gum: Synthesis, characterization and preliminary in vivo application in plant cells. Mater Sci Eng B 241:92-99 
19. Raina S, Thakur A, Sharma A, Pooja D, Minhas AP (2020) Bactericidal activity of Cannabis sativa phytochemicals from leaf extract and their derived Carbon Dots and Ag@ Carbon Dots. Mater Lett 262:127122 20. Bhamore JR, Jha S, Park TJ, Kailasa SK (2019) Green synthesis of multi-color emissive carbon dots from Manilkara zapota fruits for bioimaging of bacterial and fungal cells. J Photochem Photobiol B 191:150-155

21. Arul V, Edison TNJI, Lee YR, Sethuraman MG (2017) Biological and catalytic applications of green synthesized fluorescent N-doped carbon dots using Hylocereus undatus. J Photochem Photobiol B 168:142-148 22. Sachdev A, Gopinath P (2015) Green synthesis of multifunctional carbon dots from coriander leaves and their potential application as antioxidants, sensors and bioimaging agents. Analyst 140 (12):4260-4269

23. Shahshahanipour M, Rezaei B, Ensafi AA, Etemadifar Z (2019) An ancient plant for the synthesis of a novel carbon dot and its applications as an antibacterial agent and probe for sensing of an anti-cancer drug. Mater Sci Eng C 98:826-833

24. Atchudan R, Edison TNJI, Aseer KR, Perumal S, Lee YR (2018) Hydrothermal conversion of Magnolia liliiflora into nitrogen-doped carbon dots as an effective turn-off fluorescence sensing, multi-colour cell imaging and fluorescent ink. Colloids Surf B Biointerfaces 169:321-328

25. Sharma P, Dwivedee BP, Bisht D, Dash AK, Kumar D (2019) The chemical constituents and diverse pharmacological importance of Tinospora cordifolia. Heliyon 5 (9):e02437

26. Singh D, Chaudhuri PK (2017) Chemistry and pharmacology of Tinospora cordifolia. Nat Prod Commun 12 (2):1934578X1701200240

27. Li H, Yan X, Kong D, Jin R, Sun C, Du D, Lin Y, Lu G (2020) Recent advances in carbon dots for bioimaging applications. Nanoscale Horiz 5 (2):218-234

28. Vandarkuzhali SAA, Jeyalakshmi V, Sivaraman G, Singaravadivel S, Krishnamurthy KR, Viswanathan B (2017) Highly fluorescent carbon dots from pseudo-stem of banana plant: applications as nanosensor and bioimaging agents. Sens Actuators B Chem 252:894-900

29. Du J, Xu N, Fan J, Sun W, Peng X (2019) Carbon dots for in vivo bioimaging and theranostics. Small 15 (32):1805087

30. Boakye-Yiadom KO, Kesse S, Opoku-Damoah Y, Filli MS, Aquib M, Joelle MMB, Farooq MA, Mavlyanova R, Raza F, Bavi R (2019) Carbon dots: Applications in bioimaging and theranostics. Int J Pharm 564:308-317

31. Gudimella KK, Appidi T, Wu H-F, Battula V, Jogdand A, Rengan AK, Gedda G (2021) Sand bath assisted green synthesis of carbon dots from citrus fruit peels for free radical scavenging and cell imaging. Colloids Surf B Biointerfaces 197:111362

32. Murugan SB, Deepika R, Reshma A, Sathishkumar R (2013) Antioxidant perspective of selected medicinal herbs in India: A probable source for natural antioxidants. J Pharm Res 7 (4):271-274

33. Pavithra K, Vadivukkarasi S (2015) Evaluation of free radical scavenging activity of various extracts of leaves from Kedrostis foetidissima (Jacq.) Cogn. Food Science and Human Wellness 4 (1):42-46

34. Pham-Huy LA, He H, Pham-Huy C (2008) Free radicals, antioxidants in disease and health. Int J Biomed Sci $4(2): 89$

35. Sun X, Lei Y (2017) Fluorescent carbon dots and their sensing applications. Trends Analyt Chem 89:163-180 36. Yang D, Li L, Cao L, Zhang Y, Ge M, Yan R, Dong W-F (2021) Superior reducing carbon dots from proanthocyanidin for free-radical scavenging and for cell imaging. Analyst 
37. Jia J, Lin B, Gao Y, Jiao Y, Li L, Dong C, Shuang S (2019) Highly luminescent N-doped carbon dots from black soya beans for free radical scavenging, Fe3+ sensing and cellular imaging. Spectrochim Acta A Mol Biomol Spectrosc 211:363-372

38. Edison TNJI, Atchudan R, Shim J-J, Kalimuthu S, Ahn B-C, Lee YR (2016) Turn-off fluorescence sensor for the detection of ferric ion in water using green synthesized $\mathrm{N}$-doped carbon dots and its bio-imaging. J Photochem Photobiol B 158:235-242

39. Kailasa SK, Ha S, Baek SH, Kim S, Kwak K, Park TJ (2019) Tuning of carbon dots emission color for sensing of Fe3+ ion and bioimaging applications. Mater Sci Eng C 98:834-842

40. Venkatesan G, Rajagopalan V, Chakravarthula SN (2019) Boswellia ovalifoliolata bark extract derived carbon dots for selective fluorescent sensing of Fe3+. J Environ Chem Eng 7 (2):103013

41. Pal T, Mohiyuddin S, Packirisamy G (2018) Facile and green synthesis of multicolor fluorescence carbon dots from curcumin: in vitro and in vivo bioimaging and other applications. ACS omega 3 (1):831-843

42. Shen J, Shang S, Chen X, Wang D, Cai Y (2017) Facile synthesis of fluorescence carbon dots from sweet potato for Fe3+ sensing and cell imaging. Mater Sci Eng C 76:856-864

43. Liu Z, Chen M, Guo Y, Zhou J, Shi Q, Sun R (2020) Oxidized nanocellulose facilitates preparing photoluminescent nitrogen-doped fluorescent carbon dots for $\mathrm{Fe} 3+$ ions detection and bioimaging. Chem Eng $\mathrm{J}$ $384: 123260$

44. Lakowicz JR (2013) Principles of fluorescence spectroscopy. Springer Science \& Business Media, Switzerland AG

45. Yan F, Shi D, Zheng T, Yun K, Zhou X, Chen L (2016) Carbon dots as nanosensor for sensitive and selective detection of $\mathrm{Hg} 2+$ and 1-cysteine by means of fluorescence "Off-On" switching. Sens Actuators B Chem 224:926935

46. Yang Y, Kong W, Li H, Liu J, Yang M, Huang H, Liu Y, Wang Z, Wang Z, Sham T-K (2015) Fluorescent Ndoped carbon dots as in vitro and in vivo nanothermometer. ACS Appl Mater Interfaces 7 (49):27324-27330

47. Jhonsi MA, Thulasi S (2016) A novel fluorescent carbon dots derived from tamarind. Chem Phys Lett 661:179-184

48. Mehta VN, Jha S, Singhal RK, Kailasa SK (2014) Preparation of multicolor emitting carbon dots for HeLa cell imaging. New J Chem 38 (12):6152-6160

49. Mehta VN, Jha S, Basu H, Singhal RK, Kailasa SK (2015) One-step hydrothermal approach to fabricate carbon dots from apple juice for imaging of mycobacterium and fungal cells. Sens Actuators B Chem 213:434-443

50. Sharma N, Das GS, Yun K (2020) Green synthesis of multipurpose carbon quantum dots from red cabbage and estimation of their antioxidant potential and bio-labeling activity. Appl Microbiol Biotechnol 104 (16):71877200

51. Li H, Kang Z, Liu Y, Lee S-T (2012) Carbon nanodots: synthesis, properties and applications. J Mater Chem 22 (46):24230-24253

52. Bandi R, Gangapuram BR, Dadigala R, Eslavath R, Singh SS, Guttena V (2016) Facile and green synthesis of fluorescent carbon dots from onion waste and their potential applications as sensor and multicolour imaging agents. RSC Adv 6 (34):28633-28639

53. Gong X, Lu W, Paau MC, Hu Q, Wu X, Shuang S, Dong C, Choi MM (2015) Facile synthesis of nitrogendoped carbon dots for Fe3+ sensing and cellular imaging. Anal Chim Acta 861:74-84 
54. Huang Q, Li Q, Chen Y, Tong L, Lin X, Zhu J, Tong Q (2018) High quantum yield nitrogen-doped carbon dots: green synthesis and application as "off-on" fluorescent sensors for the determination of Fe3+ and adenosine triphosphate in biological samples. Sens Actuators B Chem 276:82-88

55. Zhu S, Meng Q, Wang L, Zhang J, Song Y, Jin H, Zhang K, Sun H, Wang H, Yang B (2013) Highly photoluminescent carbon dots for multicolor patterning, sensors, and bioimaging. Angew Chem 125 (14):40454049

56. Li W, Zhang Z, Kong B, Feng S, Wang J, Wang L, Yang J, Zhang F, Wu P, Zhao D (2013) Simple and green synthesis of nitrogen-doped photoluminescent carbonaceous nanospheres for bioimaging. Angew Chem Int Ed $52(31): 8151-8155$ 


\section{Figure captions}

Scheme 1 Schematic illustration representing the single-step synthesis of Tinospora cordifolia leaves-derived carbon dots (TCLCDs) from Tinospora cordifolia leaves aqueous extract (TCLAE)

Fig. 1 Morphology, particle size distribution, selected area electron diffraction pattern and elemental analysis of TCLCDs (a) HRTEM photomicrograph of TCLCDs at $100 \mathrm{~nm}$ scale (b) HRTEM photomicrograph of TCLCDs at $50 \mathrm{~nm}$ scale processed through ImageJ software (c) Particle size distribution chart for TCLCDs (d) SAED pattern of TCLCDs (e) EDX spectra of TCLCDs with inset data representing the elemental percentage

Fig. 2 Optical properties of TCLCDs (a) Absorption spectra of leaves-derived carbon dots (TCLCDs) and leaves aqueous extract (TCLAE) (b) Fluorescence spectra of TCLCDs at various excitation wavelength (c) Excitation and emission spectra of the TCLCDs (d) Fluorescence spectra of various concentration of TCLCDs at excitation wavelength $350 \mathrm{~nm}$ (e and f) The photographic images of texts and fluorescent patterns are written on filter paper using the aqueous solution of TCLCDs, visualized under daylight and UV-light at $365 \mathrm{~nm}$

Fig. 3 Surface functionality, crystallinity, and cell viability of cancerous cells (a) FTIR spectra of TCLCDs (b) XRD diffraction pattern of TCLCDs (c) Percentage viability of B16F10 cells in the presence of TCLAE and TCLCDs of various concentrations after 24 hours of incubation (d) percentage viability of SiHa cells in the presence of TCLAE and TCLCDs of various concentrations after 24 hours of incubation

Fig. 4 In vitro cellular imaging of cancerous cell (a) In vitro cellular imaging of melanoma (B16F10) cells under bright field, DAPI treated blue field, TCLCDs treated green field, and merged images of blue and green fields after $24 \mathrm{~h}$ treatment of TCLCDs (b) In vitro cellular imaging of cervical cancer ( $\mathrm{SiHa}$ ) cells under bright field, DAPI treated blue field, TCLCDs treated green field, and merged images of blue and green fields blue-green fields after $24 \mathrm{~h}$ treatment of TCLCDs

Fig. 5 DPPH radical scavenging assay (a) Photograph of DPPH solution upon a gradual increase in the concentration of TCLAE (b) Photograph of DPPH solution upon a gradual increase in the concentration of TCLCDs (c) UV absorption spectra of DPPH upon a gradual increment of TCLAE concentration from 0 to 0.67 $\mathrm{mg} / \mathrm{mL}$ (d) UV absorption spectra of DPPH upon a gradual increment of TCLCDs concentration from 0 to 0.583 $\mathrm{mg} / \mathrm{mL}$ (e) Percentage scavenging of DPPH radicals as a function of TCLAE concentration with inset image showing the linearity range (f) Percentage scavenging of DPPH radicals as a function of TCLCDs concentration with inset image showing the linearity range (g) DPPH scavenging percentage as a function of Vitamin C as a positive control, and (h) DPPH sensing activity of TCLCDs

Fig. $6 \mathrm{Fe}^{3+}$ sensing activity of TCLCDs (a) Relative fluorescence intensity of TCLCDs $(0.352 \mathrm{mg} / \mathrm{mL})$ in the presence of $200 \mu \mathrm{M}$ of various metal ions (b) Fluorescence spectra of TCLCDs in the presence of various concentrations $(0-1000 \mu \mathrm{M})$ of $\mathrm{Fe}^{3+}$ (c) Fluorescence intensity of TCLCDs versus concentration of $\mathrm{Fe}^{3+}$ from 0 to $1000 \mu \mathrm{M}$ (The inset image showing linearity) (d) Relative fluorescence intensity of TCLCDs (F0/F) versus concentration of $\mathrm{Fe}^{3+}$ from 0 to $100 \mu \mathrm{M}$ 
Fig. 7 Stability study results of TCLCDs (a) Photostability study of the TCLCDs under UV illumination at excitation wavelength $365 \mathrm{~nm}$ (b) Fluorescence emission spectra of various samples of TCLCDs (Previously exposed to $365 \mathrm{~nm}$ for different times) at maximum excitation wavelength $350 \mathrm{~nm}$ (c) pH-dependent stability study (d) TGA thermogram of TCLCDs

Fig. 8 Bacterial biocompatibility study of TCLAE and TCLCDs against Gram-negative: (a) Escherichia coli, (b) Edwardsiella tarda (c) Klebsiella pneumoniae, and (d) Aeromonas hydrophila and Gram-positive bacteria: (e) Enterococcus faecalis and (f) Staphylococcus aureus 
Figures
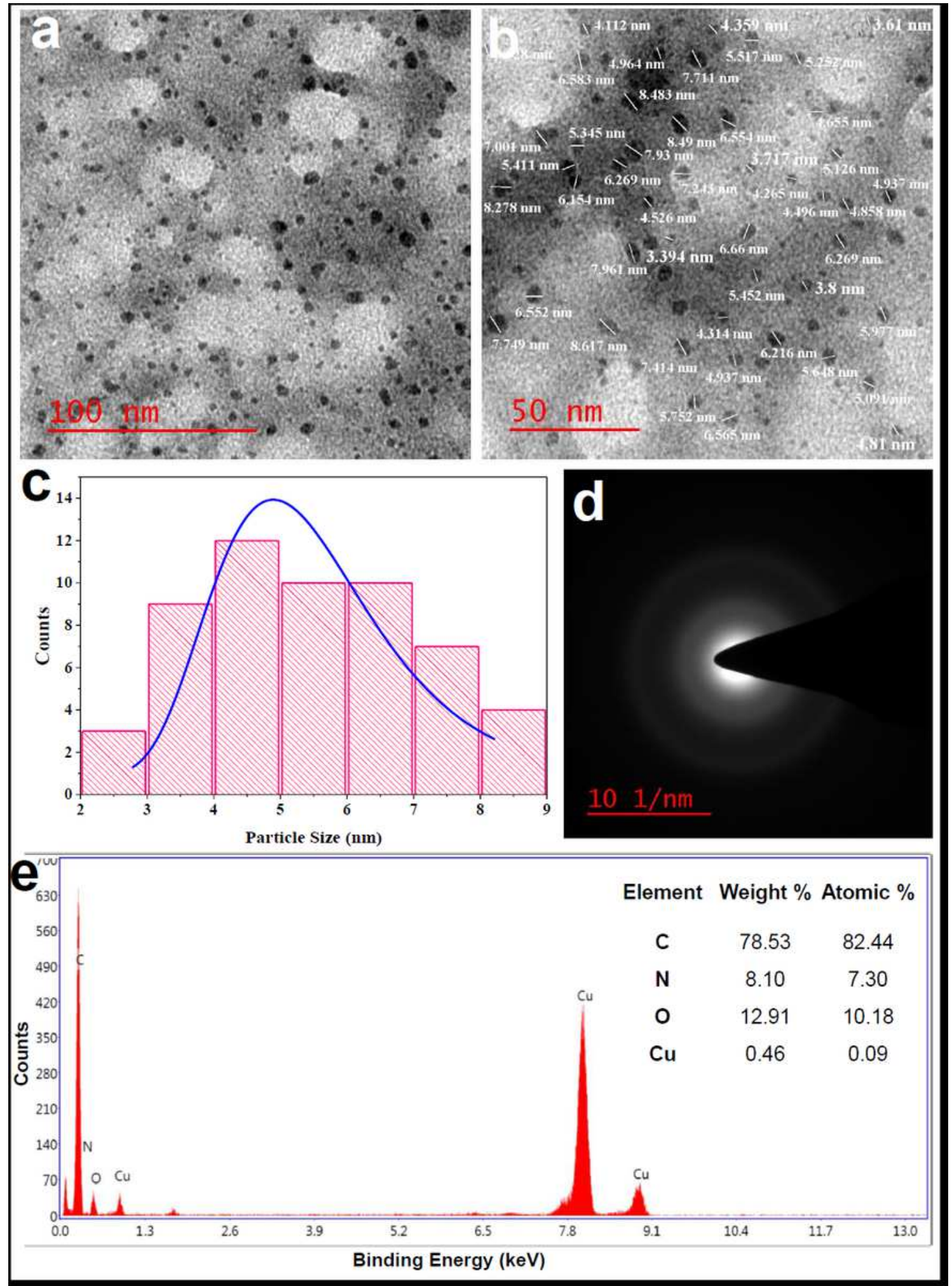

\section{Figure 1}

Morphology, particle size distribution, selected area electron diffraction pattern and elemental analysis of TCLCDs (a) HRTEM photomicrograph of TCLCDs at $100 \mathrm{~nm}$ scale (b) HRTEM photomicrograph of TCLCDs at $50 \mathrm{~nm}$ scale processed through ImageJ software (c) Particle size distribution chart for 
TCLCDs (d) SAED pattern of TCLCDs (e) EDX spectra of TCLCDs with inset data representing the elemental percentage

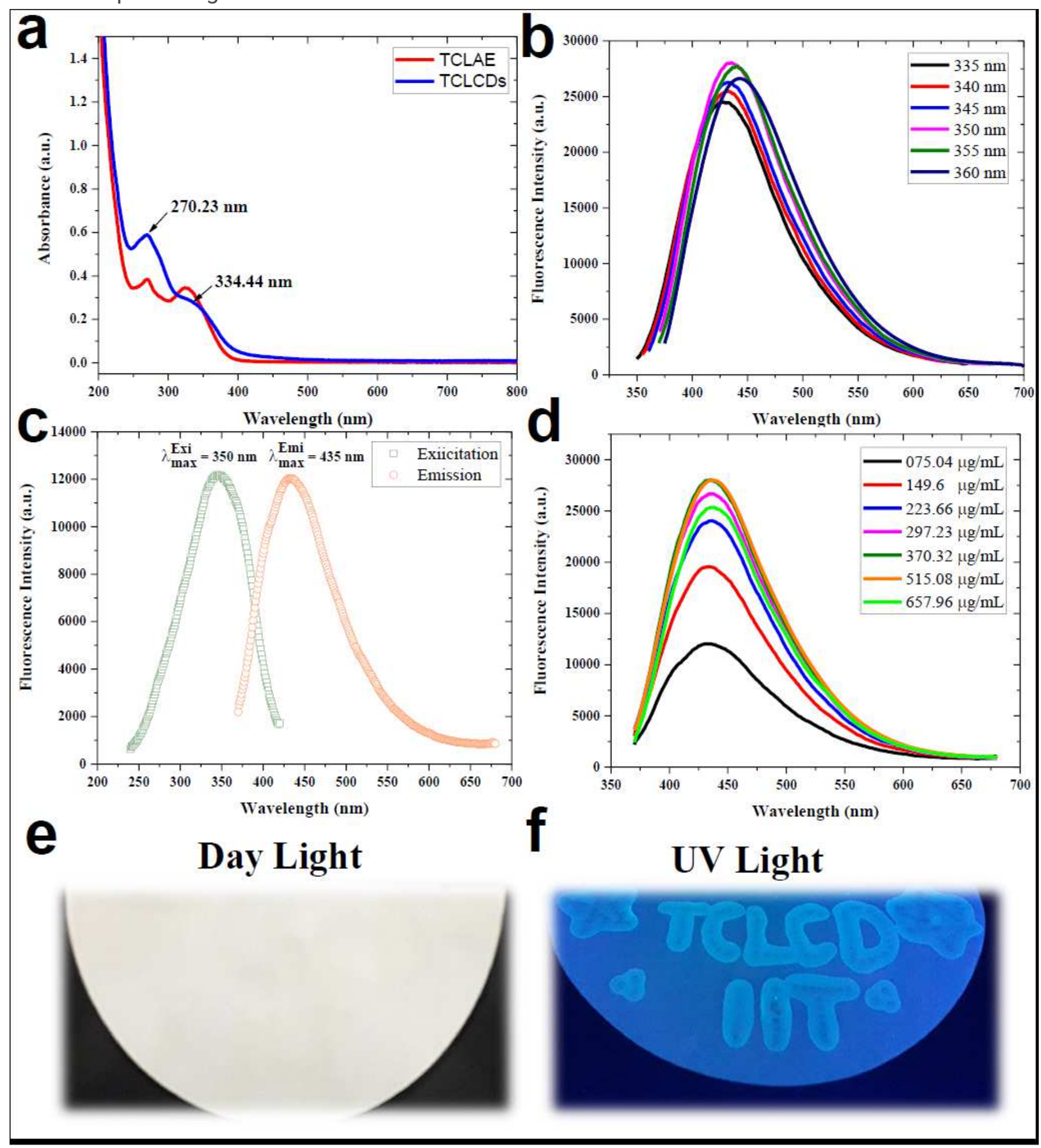

Figure 2

Optical properties of TCLCDs (a) Absorption spectra of leaves-derived carbon dots (TCLCDs) and leaves aqueous extract (TCLAE) (b) Fluorescence spectra of TCLCDs at various excitation wavelength (c) Excitation and emission spectra of the TCLCDs (d) Fluorescence spectra of various concentration of 
TCLCDs at excitation wavelength $350 \mathrm{~nm}$ (e and f) The photographic images of texts and fluorescent patterns are written on filter paper using the aqueous solution of TCLCDs, visualized under daylight and UV-light at $365 \mathrm{~nm}$
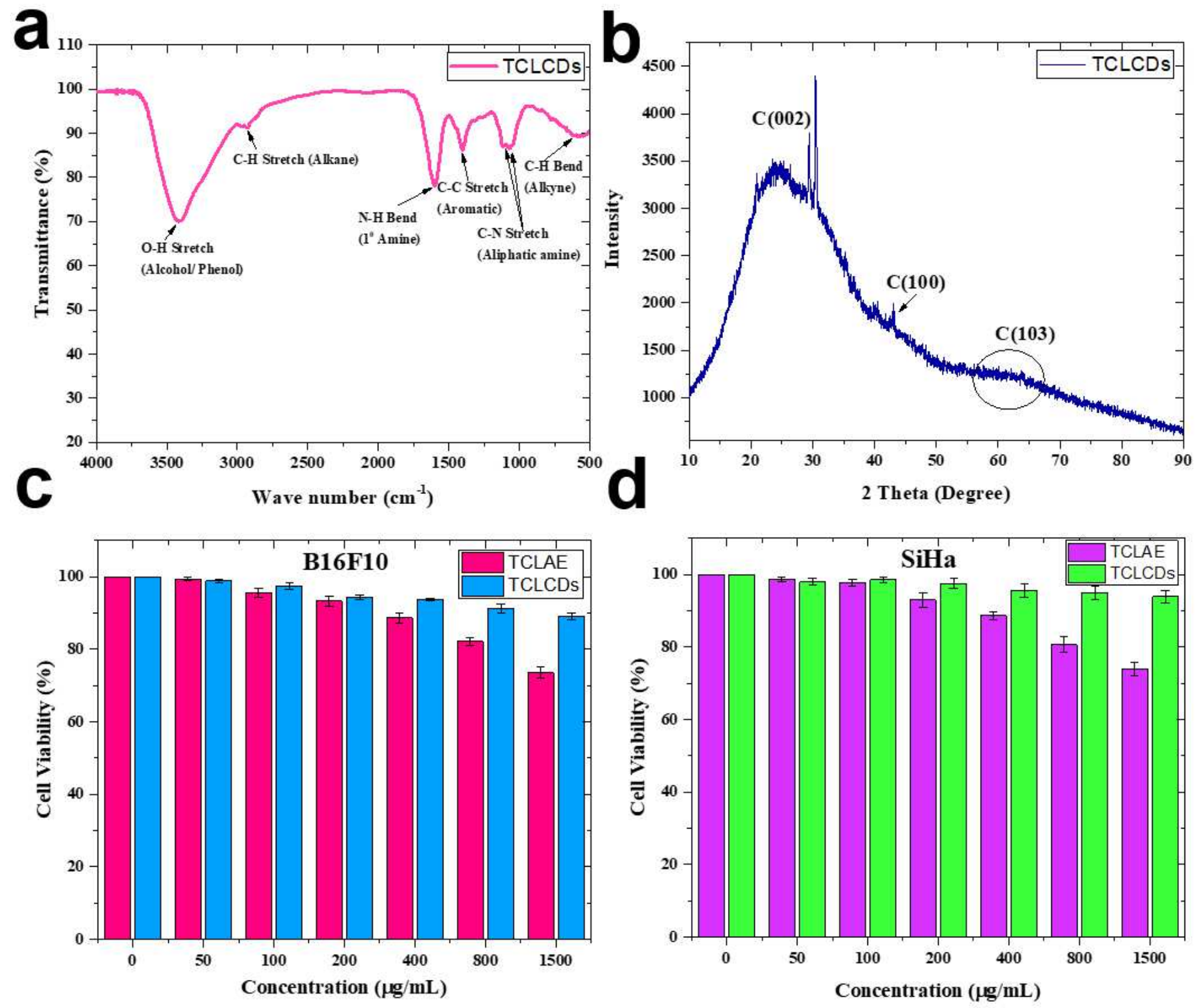

Figure 3

Surface functionality, crystallinity, and cell viability of cancerous cells (a) FTIR spectra of TCLCDs (b) XRD diffraction pattern of TCLCDs (c) Percentage viability of B16F10 cells in the presence of TCLAE and TCLCDs of various concentrations after 24 hours of incubation (d) percentage viability of SiHa cells in the presence of TCLAE and TCLCDs of various concentrations after 24 hours of incubation 


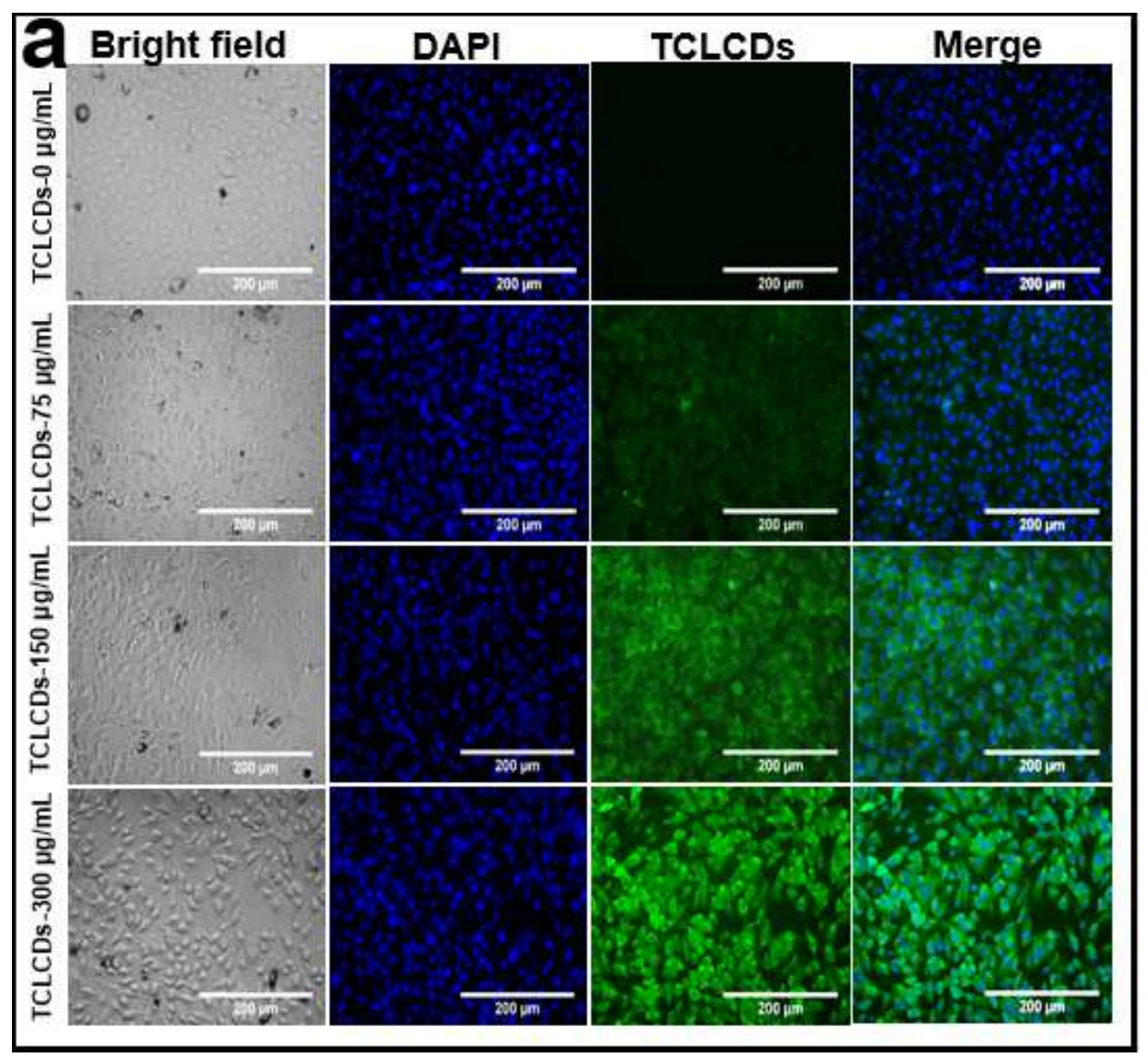

Figure 4

In vitro cellular imaging of cancerous cell (a) In vitro cellular imaging of melanoma (B16F10) cells under bright field, DAPI treated blue field, TCLCDs treated green field, and merged images of blue and green fields after $24 \mathrm{~h}$ treatment of TCLCDs (b) In vitro cellular imaging of cervical cancer ( $\mathrm{SiHa}$ ) cells under bright field, DAPI treated blue field, TCLCDs treated green field, and merged images of blue and green fields blue-green fields after $24 \mathrm{~h}$ treatment of TCLCDs 


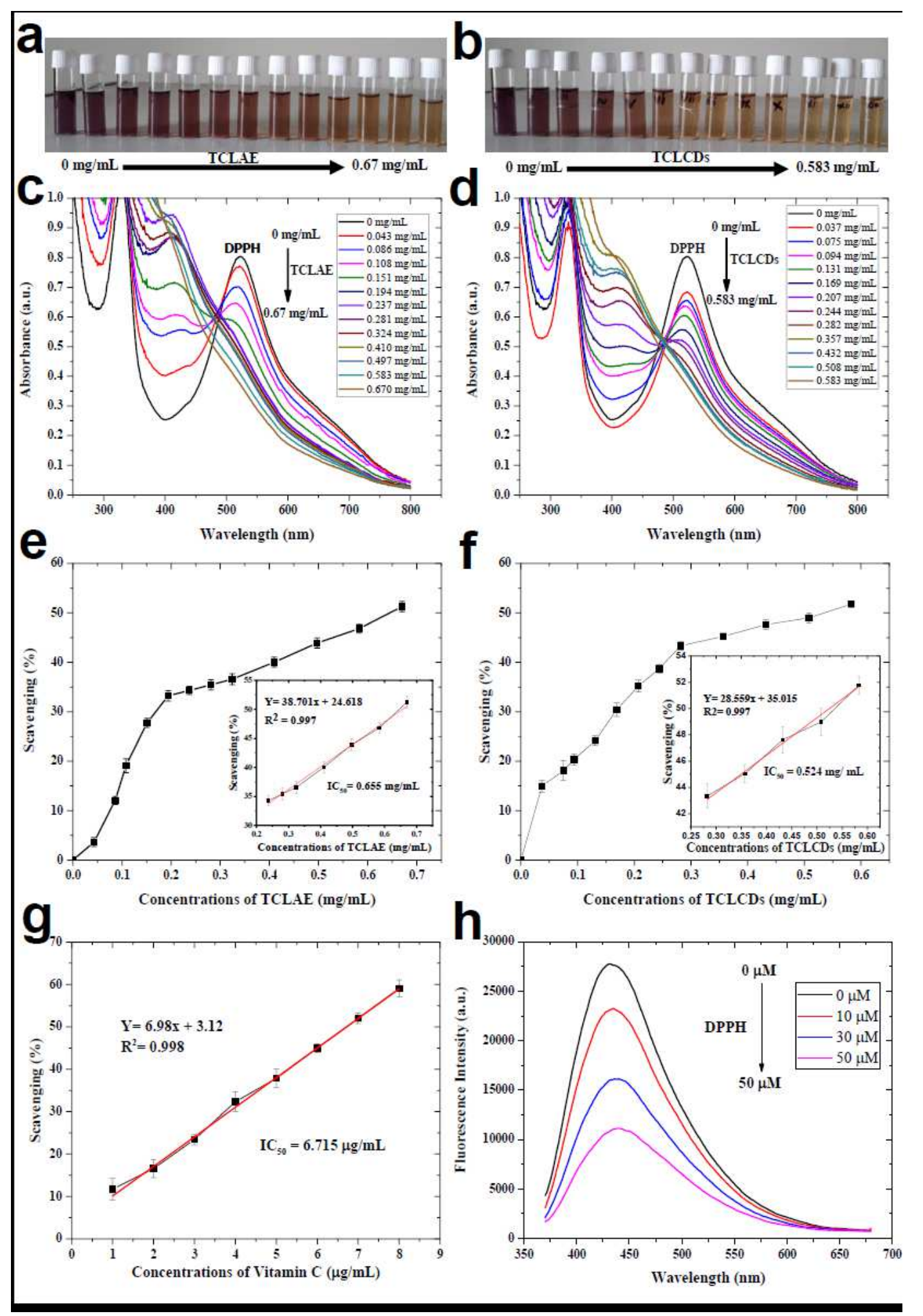

\section{Figure 5}

DPPH radical scavenging assay (a) Photograph of DPPH solution upon a gradual increase in the concentration of TCLAE (b) Photograph of DPPH solution upon a gradual increase in the concentration of TCLCDs (c) UV absorption spectra of DPPH upon a gradual increment of TCLAE concentration from 0 to $0.67 \mathrm{mg} / \mathrm{mL}$ (d) UV absorption spectra of DPPH upon a gradual increment of TCLCDs concentration from 0 to $0.583 \mathrm{mg} / \mathrm{mL}$ (e) Percentage scavenging of DPPH radicals as a function of TCLAE concentration 
with inset image showing the linearity range (f) Percentage scavenging of DPPH radicals as a function of TCLCDs concentration with inset image showing the linearity range (g) DPPH scavenging percentage as a function of Vitamin $\mathrm{C}$ as a positive control, and (h) DPPH sensing activity of TCLCDs
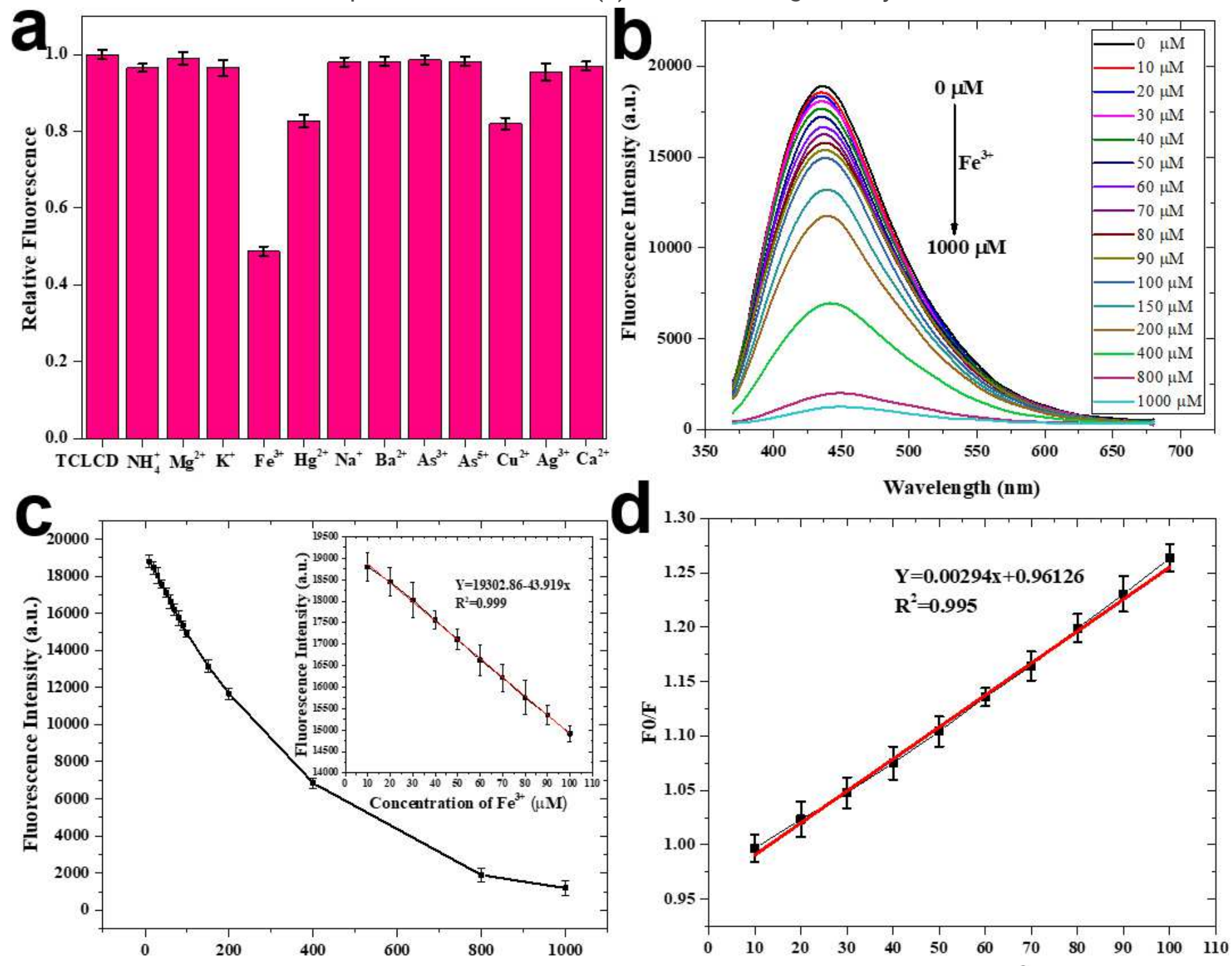

Figure 6

Fe3+ sensing activity of TCLCDs (a) Relative fluorescence intensity of TCLCDs $(0.352 \mathrm{mg} / \mathrm{mL})$ in the presence of $200 \mu \mathrm{M}$ of various metal ions (b) Fluorescence spectra of TCLCDs in the presence of various concentrations $(0-1000 \mu \mathrm{M})$ of Fe3+ (c) Fluorescence intensity of TCLCDs versus concentration of Fe3+ from 0 to $1000 \mu \mathrm{M}$ (The inset image showing linearity) (d) Relative fluorescence intensity of TCLCDs (F0/F) versus concentration of Fe3+ from 0 to $100 \mu \mathrm{M}$ 


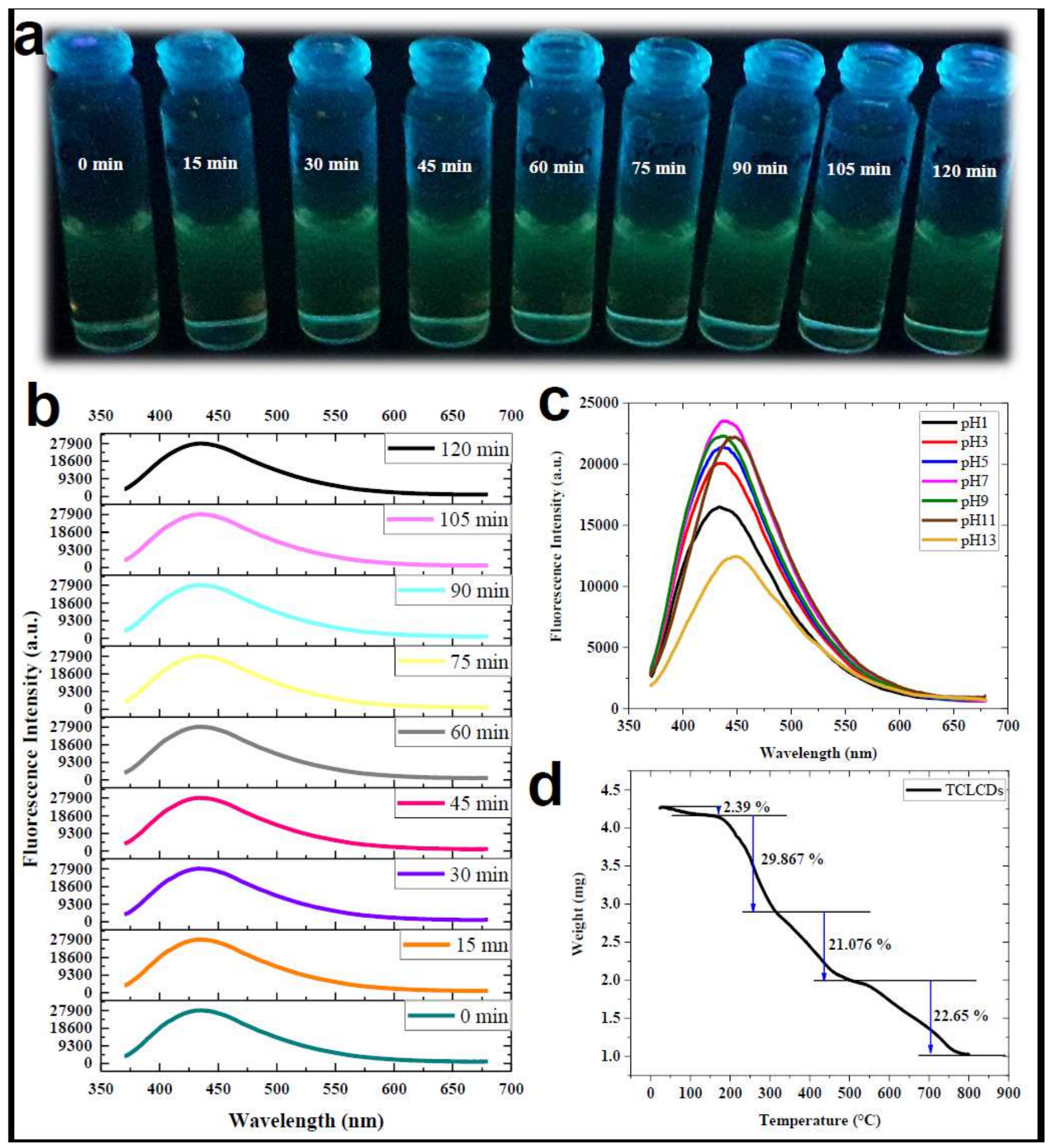

Figure 7

Stability study results of TCLCDs (a) Photostability study of the TCLCDs under UV illumination at excitation wavelength $365 \mathrm{~nm}$ (b) Fluorescence emission spectra of various samples of TCLCDs (Previously exposed to $365 \mathrm{~nm}$ for different times) at maximum excitation wavelength $350 \mathrm{~nm}$ (c) pHdependent stability study (d) TGA thermogram of TCLCDs 


\section{a}

TCLAE TCLCDS

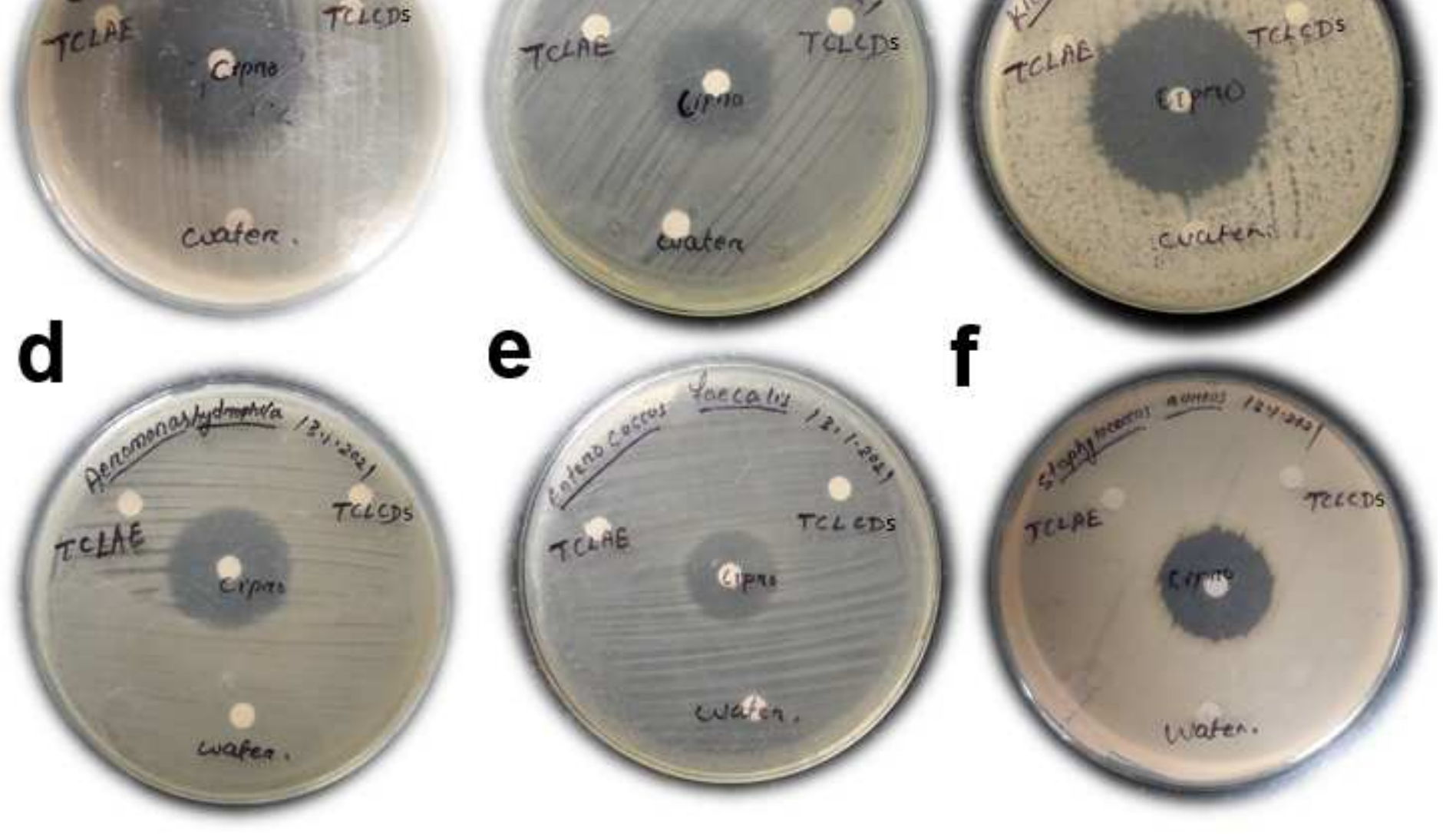

Figure 8

Bacterial biocompatibility study of TCLAE and TCLCDs against Gram-negative: (a) Escherichia coli, (b) Edwardsiella tarda (c) Klebsiella pneumoniae, and (d) Aeromonas hydrophila and Gram-positive bacteria: (e) Enterococcus faecalis and (f) Staphylococcus aureus

\section{Supplementary Files}

This is a list of supplementary files associated with this preprint. Click to download.

- Scheme1.pptx 